\title{
Stratospheric Trailing Gravity Waves from New Zealand
}

\author{
QINGFANG JiANG AND JAMES D. DOYLE \\ Marine Meteorology Division, U.S. Naval Research Laboratory, Monterey, California \\ STEPHEN D. ECKERMANN \\ Space Science Division, U.S. Naval Research Laboratory, Washington, D.C. \\ BIFFORD P. WILLIAMS \\ Boulder Division, GATS, Boulder, Colorado
}

(Manuscript received 26 September 2018, in final form 4 February 2019)

\begin{abstract}
Gravity waves are frequently observed in the stratosphere, trailing long distances from mid- to high-latitude topography. Two such trailing-wave events documented over New Zealand are examined using observations, numerical simulations, and ray-tracing analysis to explore and document stratospheric trailing-wave characteristics and formation mechanisms. We find that the trailing waves over New Zealand are orographically generated and regulated by several processes, including interaction between terrain and mountaintop winds, critical-level absorption, and lateral wave refraction. Among these, the interaction between topography and low-level winds determines the perturbation energy distribution over horizontal scales and directions near the wave source, and accordingly, trailing waves are sensitive to terrain features and low-level winds. Terrainforced wave modes are filtered by absorption associated with directional wind shear and Jones critical levels. The former plays a role in defining wave-beam orientation, and the latter sets an upper limit for the permissible horizontal wavelength of trailing waves. On propagating into the stratosphere, these orographic gravity waves are subject to horizontal refraction associated with the meridional shear in the stratospheric westerlies, which tends to elongate the wave beams pointing toward stronger westerlies and shorten the wave beams on the opposite side.
\end{abstract}

\section{Introduction}

Many early studies of gravity waves forced by flow over terrain [aka mountain waves (MWs)] have focused on the troposphere, where the dynamics are often associated with dramatic local weather phenomena such as downslope windstorms, rotors, or flight-level clearair turbulence. Commonly observed tropospheric MWs have relatively short horizontal wavelengths $(\sim 50 \mathrm{~km}$ or less) even over major barriers such as the European Alps (e.g., Smith et al. 2002) and Sierra Nevada (e.g., Doyle and Jiang 2006; Grubišić and Billings 2008). They produce either two-dimensional ridge-parallel plane waves, or three-dimensional waves induced by isolated peaks, resembling ship waves (Smith 1980). A catalogue

Corresponding author: Qingfang Jiang, qingfang.jiang@ nrlmry.navy.mil of typical MW patterns and atmospheric conditions is shown in Fig. 2 of Smith (2002).

It has been recognized for more than half a century that MWs play an important role in the global momentum budget and general circulations of the stratosphere and mesosphere (e.g., Lindzen and Holton 1968; Fels and Lindzen 1974; Lindzen 1981; Fritts and Alexander 2003). Over the past decade or two, MWs entering the stratosphere have received increasing attention because of new observations from emerging remote sensing tools (Fritts et al. 2016; Pautet et al. 2016) and advances in numerical weather prediction models that allow for the use of deep domains (Kruse and Smith 2015). In the high-latitude Southern Hemisphere during austral winter and spring, significant wave activity in the stratosphere was documented by several groups using observations from satellitemounted sensors (e.g., Wu and Waters 1996; Eckermann and Preusse 1999; Jiang et al. 2002; Hendricks et al. 2014). Local maxima in stratospheric wave perturbation 
amplitudes, or "hot spots" (Hoffmann et al. 2013), were found in the vicinity of major barriers such as the Southern Andes and Antarctic Peninsula, implying orographic origins. However, some maxima are located over the Southern Ocean far from underlying terrain, and their sources are still not well understood. Possibilities include small-island terrain such as the South Georgia Island (e.g., Alexander et al. 2009; Alexander and Grimsdell 2013; Vosper 2015) and the Auckland Islands (Eckermann et al. 2016), synoptic-scale instabilities associated with baroclinic storm systems (Hendricks et al. 2014), and long downstream propagation of waves from terrain sources such as the Southern Andes (Preusse et al. 2002; Shutts and Vosper 2011; Sato et al. 2012; Jiang et al. 2013, 2014). These hot-spot maxima over the Southern Ocean derived from satellite observations may be related to the "missing drag" inferred near $60^{\circ} \mathrm{S}$ in general circulation and climate models as the source of a cold-pole bias that delays vortex breakdown in the stratosphere (McLandress et al. 2012; Garfinkel and Oman 2018).

The nonlocal orographic source hypothesis has been supported by several recent studies, which discovered quasi-linear isolated wave groups, or "beams" (Gregory and Sutherland 2010), extending thousands of kilometers downstream of terrain and toward $60^{\circ} \mathrm{S}$, in the stratosphere from either satellite imagery or numerical simulations (e.g., Wu and Eckermann 2008; Alexander and Teitelbaum 2011; Shutts and Vosper 2011; Jiang et al. 2013; Ehard et al. 2017). These so-called stratospheric trailing waves (STWs; Fritts et al. 2016; Ehard et al. 2017) share the following common characteristics, mostly in contrast to MWs in the troposphere. First, they have much longer horizontal wavelengths $(\sim 100$ $600 \mathrm{~km})$, about one order of magnitude longer than typical MWs in the troposphere. Second, they can extend up to $1000 \mathrm{~km}$ from their plausible wave source, unlike propagating MWs (i.e., untrapped MWs) in the troposphere, which remain close to their parent terrain. Third, in contrast to classical left-right-symmetric (i.e., with respect to the mean winds) three-dimensional hydrostatic or trapped MWs over an isolated peak (Smith et al. 2002), STWs are highly asymmetric and often observed only on one side of the terrain. Furthermore, STWs are most commonly observed over topography located to the south of $40^{\circ} \mathrm{S}$, where stratospheric winds are characterized by strong westerlies with a significant meridional shear. These wave beams seemingly emit from topography and extend southeastward toward the stratospheric jet maximum (or northeastward from terrain, located poleward of $60^{\circ} \mathrm{S}$, such as the Antarctic Peninsula).

While STWs have been documented in recent studies, overall, they are far less studied than their counterparts in the troposphere, and key questions remain unanswered regarding their origin, characteristics, formation mechanisms, and significance in transferring momentum into the stratosphere and mesosphere. One of the objectives of the Deep Propagating Gravity Wave Experiment (DEEPWAVE) that took place over New Zealand (NZ) area in the austral winter of 2014 was to improve our understanding of STWs near the Southern Alps of NZ (Fritts et al. 2016), which extend along the South Island with multiple peaks over $3 \mathrm{~km}$ above sea level (MSL). During the 6-week-long field observations, STWs were documented extending from $\mathrm{NZ}$ to the east during several DEEPWAVE intensive observational periods [IOPs; see Table 4 of Fritts et al. (2016)]. Two such STW IOPs are examined here, namely, IOPs 3 and 6, with more emphasis on the latter. To deepen our understanding of STW dynamics, an in-depth analysis of two STW events is presented using observations and real-data numerical simulations.

The remainder of this paper is organized as follows. Section 2 includes a brief description of the model configuration and the synoptic conditions for the two STW events. The characteristics of simulated STWs are illustrated in section 3 based on observations and numerical simulations. The vertical variation of STWs and associated momentum flux are analyzed in section 4 . The sensitivity of STWs to underlying topography and low-level wind directions is investigated in section 5 using multiple sensitivity simulations and spectral analysis. The role of meridional shear of the horizontal wind in changing the characteristics of STWs is examined in section 6 based on ray-tracing calculations. Section 7 contains concluding remarks.

\section{Model configuration and synoptic conditions}

\section{a. Model configuration}

The atmospheric and adjoint components of the Coupled Ocean-Atmospheric Mesoscale Prediction System (COAMPS; ${ }^{1}$ Hodur 1997; Doyle et al. 2011) were applied to the DEEPWAVE study area to provide real-time forecast guidance during the field campaign period (Fritts et al. 2016). COAMPS is a fully compressible, nonhydrostatic terrain-following mesoscale model. The finite-difference schemes are of secondorder accuracy in time and space in this application. The boundary layer and free-atmospheric turbulent mixing and diffusion are represented using a prognostic

\footnotetext{
${ }^{1}$ COAMPS is a registered trademark of the Naval Research Laboratory.
} 
equation for the turbulence kinetic energy budget following Mellor and Yamada (1974) and Thompson and Burk (1991). The surface heat and momentum fluxes are computed following Louis (1979) and Louis et al. (1982). The gridscale evolution of the moist processes is explicitly predicted from budget equations for cloud water, cloud ice, rainwater, snowflakes, and water vapor (Rutledge and Hobbs 1983), and the subgrid-scale moist convective processes are parameterized using an approach based on Kain and Fritsch (1993). A $\delta$-four-stream approximation is used for the short- and longwave radiation processes (Fu et al. 1997).

The initial fields for the model are created from a threedimensional variational data assimilation (i.e., 3DVAR) method (Daley and Barker 2001). Lateral boundary conditions for the outermost grid mesh are derived from Navy Global Environmental Model (NAVGEM) forecast fields (Hogan et al. 2014). The computational domain contains two horizontally nested grid meshes of $256 \times 150$ and $433 \times 358$ grid points, and the corresponding horizontal grid spacings are 36 and $12 \mathrm{~km}$, respectively. The inner domain covers New Zealand, Tasmania, the southeastern tip of Australia, and surrounding oceans (Fig. 1). There are 86 model levels in the vertical on a nonuniform sigma grid. The model top is located approximately at $60 \mathrm{~km}$ MSL with a sponge boundary condition (Klemp and Durran 1983) applied to the uppermost $15 \mathrm{~km}$ of the domain to reduce reflection of gravity waves. The terrain data are based on the Global Land One-km Base Elevation (GLOBE) dataset, and are shown for the 12-km mesh in Fig. 1. For IOPs 3 and 6, the model is initialized at 0000 UTC 12 and 18 June 2014, respectively, and after a 12-h data assimilation cycle, a 48 -h forecast is performed.

\section{b. Synoptic conditions for IOPs 6 and 3}

The DEEPWAVE IOP 6 took place on 19 June 2014, when a deep trough was located on the eastern side of $\mathrm{NZ}$ along with a pressure ridge to the northwest. Associated with this trough-ridge pair, a strong southwesterly (SSW) jet impinges on the NZ topography (Fig. 2a). This SSW jet extends from the surface to the tropopause (Figs. 2a,b) and persists throughout IOP 6. The winds in the lower stratosphere are southwesterly to the west and northwesterly to the east of NZ (Fig. 2c), and predominantly westerly in the midstratosphere and above, implying an approximately $75^{\circ}$ clockwise turning of the wind direction from the mountaintop level $(\sim 3 \mathrm{~km})$ to the midstratosphere. The wind speed in the stratosphere exhibits a pronounced negative meridional shear (i.e., $\partial U / \partial y<0$, where $U$ denotes the zonal wind component; Fig. 2d) with much stronger winds to the south of $40^{\circ} \mathrm{S}$.

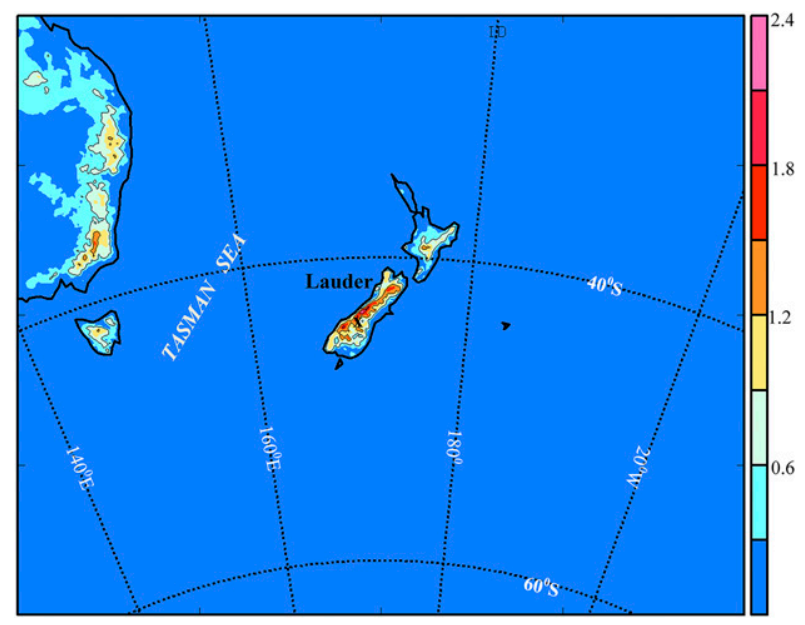

FIG. 1. The model terrain for the 12-km COAMPS grid (color shading; interval: $0.3 \mathrm{~km}$ ). The radiosonde site at Lauder is indicated by the " $\mathrm{x}$ " symbol.

The IOP 3 took place on 14 June, associated with a shallow trough to the south of NZ, which directed northwesterly (NW) flow toward the southern tip of the South Island (Fig. 3a), in contrast to the prevailing SSW flow in the troposphere during IOP 6 (cf. Fig. 2a). Under the influence of a cutoff low located to the east, the mountaintop wind speed is relatively weak over the northern half of NZ. The northwesterly jet over the southern tip of NZ extends to the tropopause (Fig. 3b), above which the winds become more westerly (Fig. 3c), implying a $45^{\circ}$ anticlockwise turning from the troposphere to the stratosphere. In the midstratosphere, the winds are predominantly westerly with a strong negative meridional shear (Fig. 3d), qualitatively similar to those during IOP 6.

\section{STW characteristics and model validation}

STWs are evident in 2-hPa brightness temperature perturbation fields derived from measurements obtained by the Atmospheric Infrared Sounder (AIRS) onboard the National Aeronautics and Space Administration (NASA) Aqua satellite on 14 and 19 June 2014 (Fig. 4). Large-scale variation has been removed to isolate mesoscale wave perturbations using the techniques described in Eckermann and Wu (2012) and Eckermann et al. (2019, manuscript submitted to J. Appl. Meteor. Climatol.). The AIRS imagery reveals several ascent-descent pairs (note that the warmer colors correspond to higher brightness temperatures, or downward displacement of isentropes, and colder colors correspond to the lower brightness temperatures and upward isentropic displacement), associated with gravity wave-induced vertical motion. Several aspects of the STWs revealed by the 

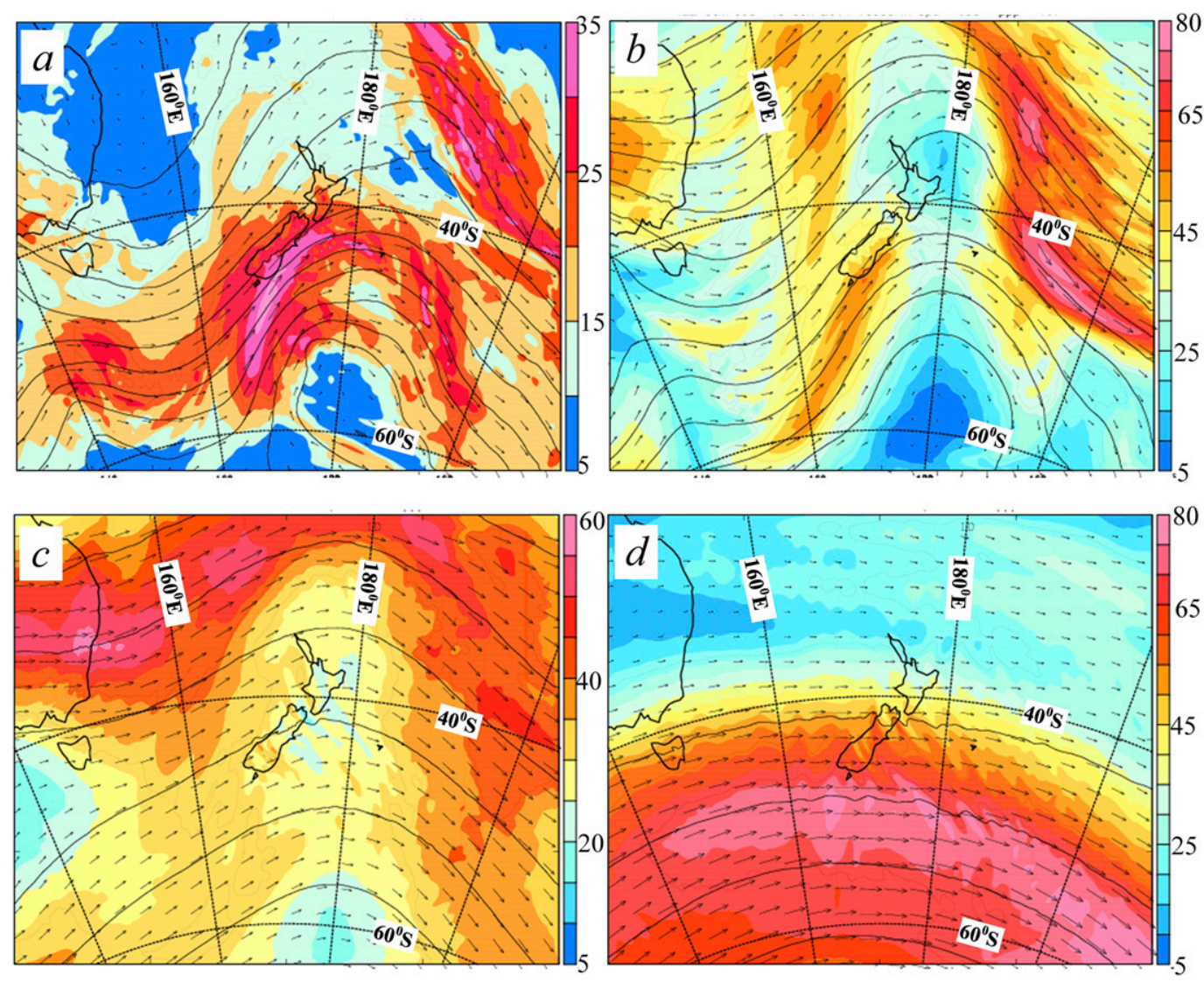

FIG. 2. The wind speed (color shading; interval: $5 \mathrm{~m} \mathrm{~s}^{-1}$ ), wind vectors, and pressure (contours; interval: $5 \mathrm{hPa}$ ) at (a) 3, (b) 10, (c) 15, and (d) $30 \mathrm{~km}$ MSL from the 12-km COAMPS grid, valid at 1200 UTC 19 Jun 2014.

AIRS imagery are worth noting: 1) They appear to be located near NZ terrain, implying their likely orographic origin. 2) These waves have relatively long horizontal wavelengths compared with tropospheric MWs. The wavelengths estimated from the distance between two adjacent temperature maxima (or minima) are between 200 and $400 \mathrm{~km}$, which are one order of magnitude larger than those of MWs observed in the troposphere over midlatitude barriers such as the Southern Alps (Lane et al. 2000), the Alps (Smith et al. 2002; Volkert et al. 2003), and the Sierra Nevada (Doyle and Jiang 2006; Grubišić and Billings 2008). 3) While there are STW beams on both sides of NZ, the ones on the southeastern side are significantly broader than their counterparts on the northern side. This north-south asymmetry is more striking in Fig. 4c (i.e., IOP 6) with the southern STW beams visible more than $1500 \mathrm{~km}$ away from NZ topography. Their counterparts to the north only extend a few hundred kilometers from NZ. 4) These waves persist for $10 \mathrm{~h}$ or longer with relatively small changes in their characteristics. 5) It is interesting to compare the imaged STWs in IOP 3 and IOP 6. There are fewer visible beams in IOP 3 than in IOP 6 , and the orientations of the STW phase lines are noticeably different between the two events as well. For IOP 3, phase lines are oriented southwestward, approximately $60^{\circ}-70^{\circ}$ from the east. For IOP 6, this angle is much smaller (i.e., $\sim 40^{\circ}$ ).

As depicted in Fig. 5a, the NSF/NCAR Gulfstream V High-performance Instrumented Airborne Platform for Environmental Research (GV HIAPER) aircraft flew a box pattern over the downstream (i.e., southeastern) side of NZ (see Fig. 5a) during IOP 6 as research flight 7 (RF07). Flight-level temperatures $(z \sim 12 \mathrm{~km})$ on leg 3 , located closest to NZ, show clear evidence of gravity waves with horizontal wavelengths $\sim 200 \mathrm{~km}$ (Fig. 5d), especially within the region of flight-leg distances $\sim 400$ $900 \mathrm{~km}$ where strong STWs are also seen both in AIRS (Figs. 4c,d and 5c) and in upper-stratospheric lidar temperatures measured from the aircraft (Fig. 5b). For the three flight legs (legs 5-7) farther to the southeast in Fig. 5a, clear STW oscillations are again seen in aircraft lidar temperatures (Fig. 5e) and in AIRS brightness temperatures (Fig. 5f), whereas wave signals are noticeably weaker in the flight-level temperatures in Fig. 5g. 



FIG. 3. The wind speed (color shading; interval: $5 \mathrm{~m} \mathrm{~s}^{-1}$ ), wind vectors, and pressure (contours; interval: $5 \mathrm{hPa}$ ) at (a) 3 , (b) 10 , (c) 15 , and (d) $30 \mathrm{~km}$ above sea level from the 12-km COAMPS grid, valid at 1200 UTC 14 Jun 2014.

In Fig. 6, model-simulated wind and potential temperature profiles are compared with those derived from radiosondes launched from Lauder (see Fig. 1 for location) on 19 June 2014 during IOP 6. The wind profiles indicate strong persistent west-southwesterlies throughout most of the troposphere with wind speed ranging from $30 \mathrm{~m} \mathrm{~s}^{-1}$ near the mountaintop level to $45 \mathrm{~m} \mathrm{~s}^{-1}$ near the $10-\mathrm{km}$ level. Following Reinecke and Durran (2008), we computed the vertically averaged upstream wind speed and buoyancy frequency over the lowest $3 \mathrm{~km}$ to be $\sim 20 \mathrm{~m} \mathrm{~s}^{-1}$ and $0.01 \mathrm{~s}^{-1}$, respectively. Using $h_{m}=3 \mathrm{~km}$ for the average peak mountain height, we obtain the nondimensional mountain height $\hat{h}=N h_{m} / U \sim 1.5$. This value implies a strong nonlinear wave response, with possible flow splitting to the north and south and enhanced "high drag" MW forcing near the surface (e.g., Smith 1989; Eckermann et al. 2010). In the stratosphere, the wind speed increases from a local minimum of $\sim 30 \mathrm{~m} \mathrm{~s}^{-1}$ at the tropopause to $\sim 100 \mathrm{~m} \mathrm{~s}^{-1}$ at $45 \mathrm{~km}$ MSL. Directional wind shear is evident across the upper troposphere-lower stratosphere (UTLS; located between $\sim 10$ and $20 \mathrm{~km}$ ). The potential temperature profile exhibits a sudden increase near $12 \mathrm{~km}$, where the tropopause is located. The three radiosondes only reached $\sim 25 \mathrm{~km}$ MSL, below which the agreement between radiosonde measurements and COAMPS simulations is satisfactory.

The vertical velocity fields obtained from the COAMPS simulations at four different levels for IOPs 6 and 3 are shown in Figs. 7 and 8, respectively. It is evident that for both IOPs, the simulated $w$ patterns at the $45-\mathrm{km}$ level are in qualitative agreement with the AIRS observations (Figs. 4, 7d, and 8d). For example, the simulated STW wavelengths and phase-line orientations for both IOPs compare favorably with those from the AIRS imagery. COAMPS results in Figs. 7c and $7 \mathrm{~d}$ show that STWs do not extend far to the southeast with significant amplitude at $15 \mathrm{~km}$, but do at $45 \mathrm{~km}$. This is consistent with the RF07 observations in Fig. 5, which showed strong wave responses at $12 \mathrm{~km}$ only for the flight leg close to the terrain (cf. Figs. 5d and $5 \mathrm{~g}$ ), whereas both AIRS and the lidar data showed strong wave responses near $45 \mathrm{~km}$ on all flight legs (Figs. 5b,c,e,f). 
(a) 14 June 2014 Descending $2 \mathrm{hPa} 1319$ UTC

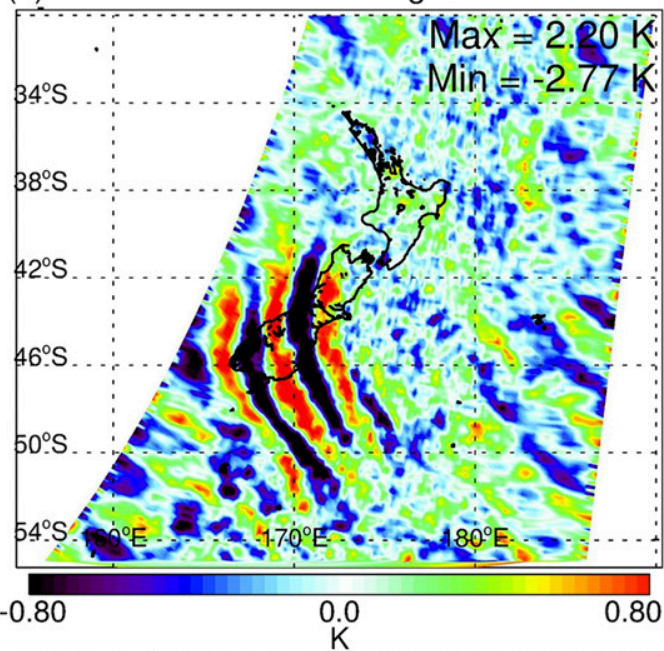

(c) 19 June 2014 Ascending $2 \mathrm{hPa} 0231$ UTC

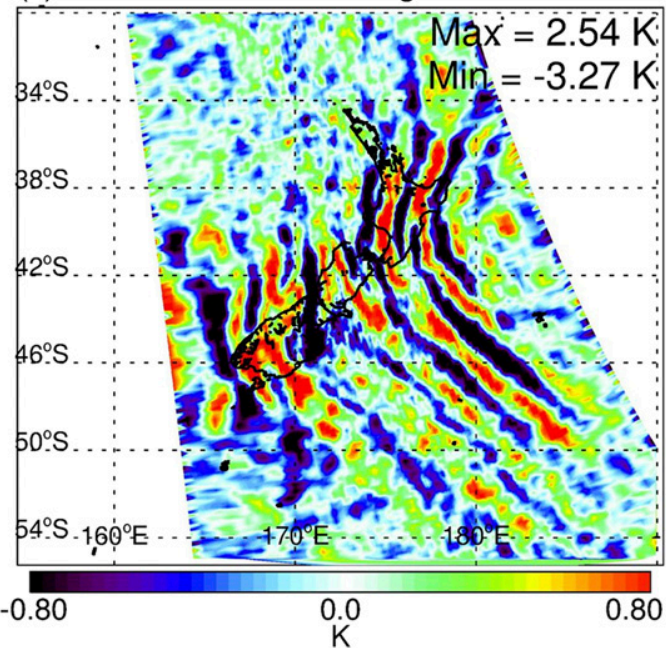

(b) 15 June 2014 Ascending $2 \mathrm{hPa} 0255$ UTC

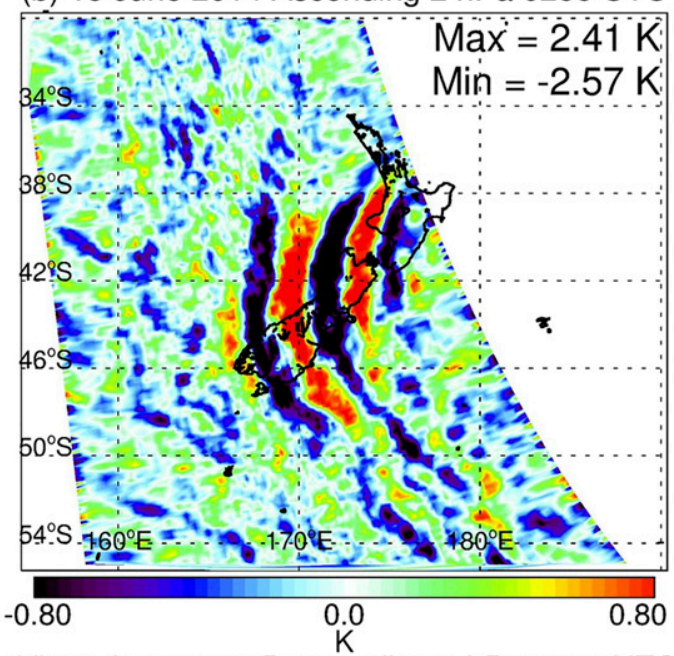

(d) 19 June 2014 Descending $2 \mathrm{hPa} 1337$ UTC

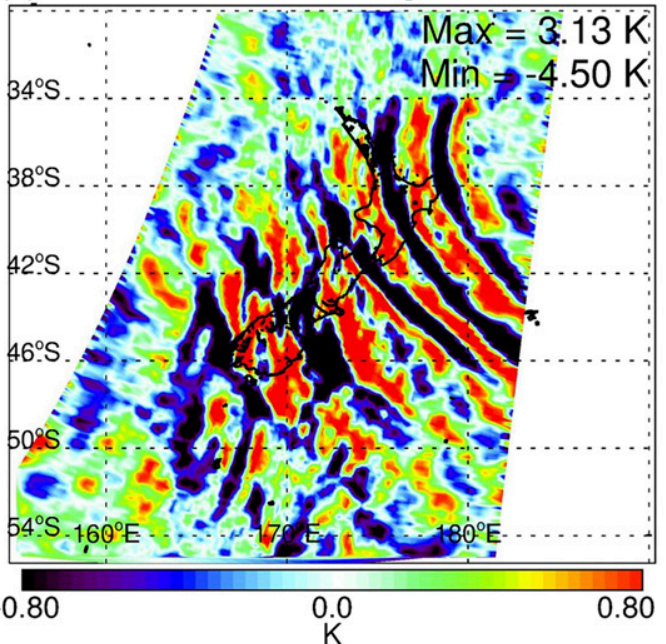

FIG. 4. Brightness temperature perturbations (K; see color bars) derived from AIRS $15-\mu \mathrm{m}$ channel-74 nadir radiances, which peaks near the 2-hPa level, for overpasses on (a) 1319 UTC 14 Jun (descending), (b) 0255 UTC 15 Jun (ascending), (c) 0231 UTC 19 Jun (ascending), and (d) 1337 UTC 19 Jun (descending) 2014. Maximum and minimum values in each panel are given at the top right.

The agreement between the COAMPS simulation and observations from AIRS, RF07, and radiosondes implies that COAMPS captures both the large-scale flow structure and mesoscale gravity wave response in the stratosphere reasonably well.

\section{Vertical variations of wave momentum fluxes}

Encouraged by the agreement between the real-data COAMPS simulation [referred to as control (CNTRL)] and observations, we further examine the dynamics and characteristics of these STWs and their role in vertical momentum transfer through diagnosis of the COAMPS simulations.
We begin by examining the vertical variation of the simulated wave fields during IOP 6 (Fig. 7). In the midand upper troposphere, the winds over the Southern Alps are southwesterly, approximately parallel to the main Southern Alps ridge (cf. Fig. 2 and 6). The vertical velocity in the troposphere is characterized by quasitwo-dimensional waves directly over NZ with phases aligned northwest-southeastward. The horizontal wave vector points southwestward, approximately opposite to the tropospheric wind direction (Figs. 7a,b). The vertical velocity exhibits multiple maxima directly over $\mathrm{NZ}$ and decays rapidly with offshore distance. Careful inspection of the actual terrain suggests that there is close correspondence between the wave phase lines and high peaks 
(a) RF07 19 June 2014

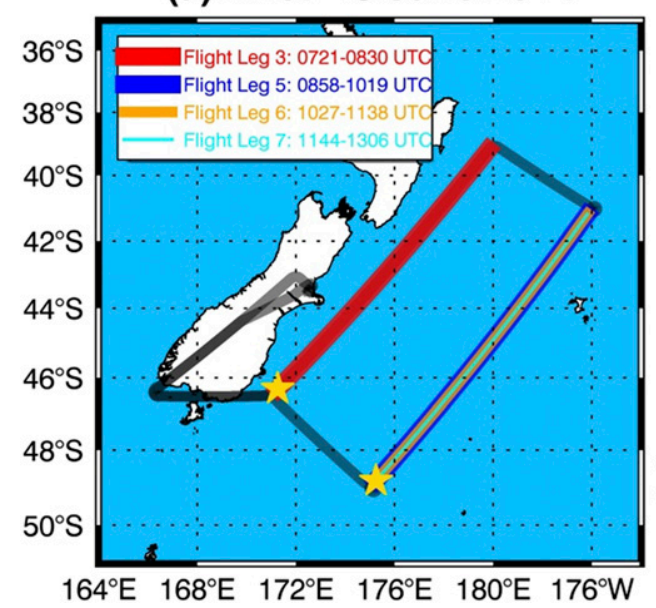

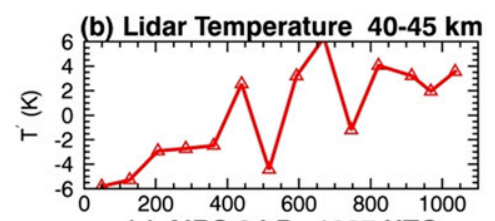

(c) AIRS 2 hPa 1337 UTC

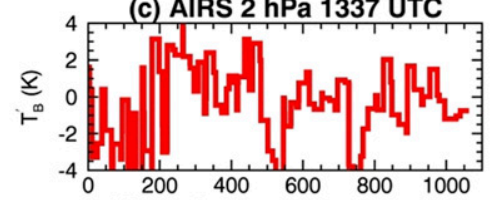

(d) Flight-Level Temperature

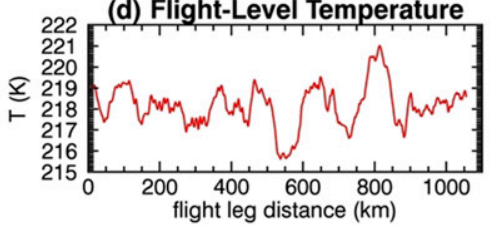

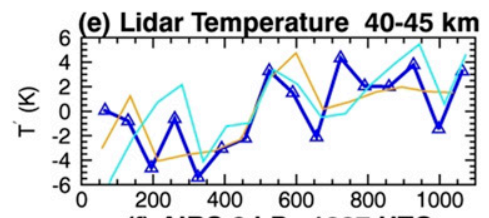
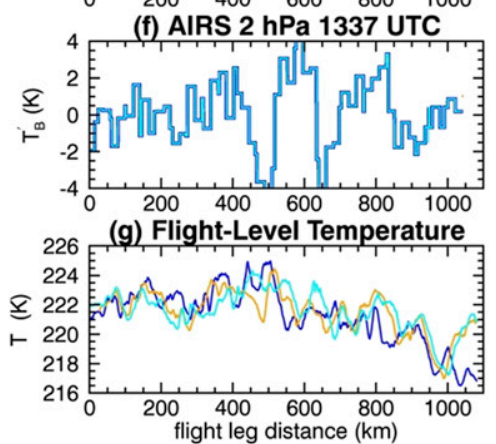

FIG. 5. (a) Ground track of GV HIAPER RF07 (gray curves) on 19 Jun 2014, with flight legs 3, 5, 6, and 7 marked in red, blue, orange, and cyan, respectively. (right) Perturbations as a function of flight distance along the separate flight legs from the reference points marked by stars in (a): (b),(e) GV HIAPER Rayleigh lidar temperatures from 40- to 45-km altitude; (c),(f)AIRS 2-hPa brightness-temperature perturbations from Fig. 4d; and (d),(f) flight-level temperatures measured in situ by the GV HIAPER, after 60-point along-track smoothing of 1 -s time series.

underneath, suggesting that individual peaks are likely sources of these waves. In the UTLS, the wave fields extend farther offshore and are more parabolic (Fig. 7c), resembling typical hydrostatic waves over an isolated peak (e.g., Smith 1980), while approximately maintaining their left-right symmetry with respect to the primary terrain ridge. Directly over and to the northwest of NZ, the waves are qualitatively similar to their tropospheric counterparts. On the downwind side, the wave fronts extend southeastward over a distance of $\sim 2000 \mathrm{~km}$ at the $45-\mathrm{km}$ level (Fig. 7d), taking on the form of ribbonlike STWs. The vertical velocity amplitudes become much larger at the $45-\mathrm{km}$ level because of the decrease of the background air density $\overline{\rho_{a}}$ with height.

For IOP 3, the modeled tropospheric waves include shorter ridge-parallel waves over NZ and longer waves emitted from the southern tip of the South Island (Figs. 8a,b). In the midstratosphere, while the ridgeparallel waves become less pronounced, the northwestsoutheast-oriented waves become longer and more intense with increasing altitude, developing into STWs in the midstratosphere (Figs. 8c,d).

From a gravity wave drag parameterization perspective, two critical questions are how much momentum STWs carry and where it is dissipated. The waveinduced vertical fluxes of horizontal momentum $\mathbf{F}=\left(F_{x}, F_{y}\right)$ and total energy $\mathbf{E}=\left(E_{x}, E_{y}, E_{z}\right)$ are defined as (e.g., Kruse and Smith 2015)

$$
\left(F_{x}, F_{y}\right)=\overline{\rho_{a}}\left(\overline{u^{\prime} w^{\prime}}, \overline{v^{\prime} w^{\prime}}\right)
$$

and

$$
\left(E_{x}, E_{y}, E_{z}\right)=\left(\overline{u^{\prime} p^{\prime}}, \overline{v^{\prime} p^{\prime}}, \overline{w^{\prime} p^{\prime}}\right)
$$

where $\left(u^{\prime}, v^{\prime}, w^{\prime}\right)$ and $p^{\prime}$ denote the wave-induced perturbation velocity and pressure, respectively, and $\overline{\rho_{a}}$ is the horizontally averaged air density at a given height. Here the primed terms are defined as $\phi^{\prime}(x, y)=\phi(x, y)-\bar{\phi}$, where the overbar denotes a moving average over a circle centered at $(x, y)$ with a radius of $R=300 \mathrm{~km}$. Trial calculations using $R=250$ and $350 \mathrm{~km}$ suggest that wave fluxes are relatively insensitive to the chosen $R$ value.

The vertical fluxes of zonal momentum $F_{x}$ at four different levels, namely 9 (below tropopause), 15 (above the tropopause), 25 (midstratosphere), and $45 \mathrm{~km}$ (upper stratosphere), are shown for IOP 6 in Fig. 9. In the troposphere, $F_{x}$ is negative, corresponding to upwardpropagating quasi-stationary MWs transporting easterly wave momentum against the westerly mean flow. There are two localized $\left|F_{x}\right|$ maxima in Fig. 9a; one is located right over the Southern Alps, apparently associated with MWs excited by the NZ terrain, and the other is located to the east in the vicinity of the leading edge of the subtropical jet, suggesting its origin could be from jet stream or frontal imbalances. Just above the tropopause, the momentum flux maximum over NZ in Fig. 9b resembles its counterpart below the tropopause but with a reduced magnitude (Fig. 9b). In addition to the maximum over NZ, a weak region of negative momentum flux now extends southeastward, consistent with the 


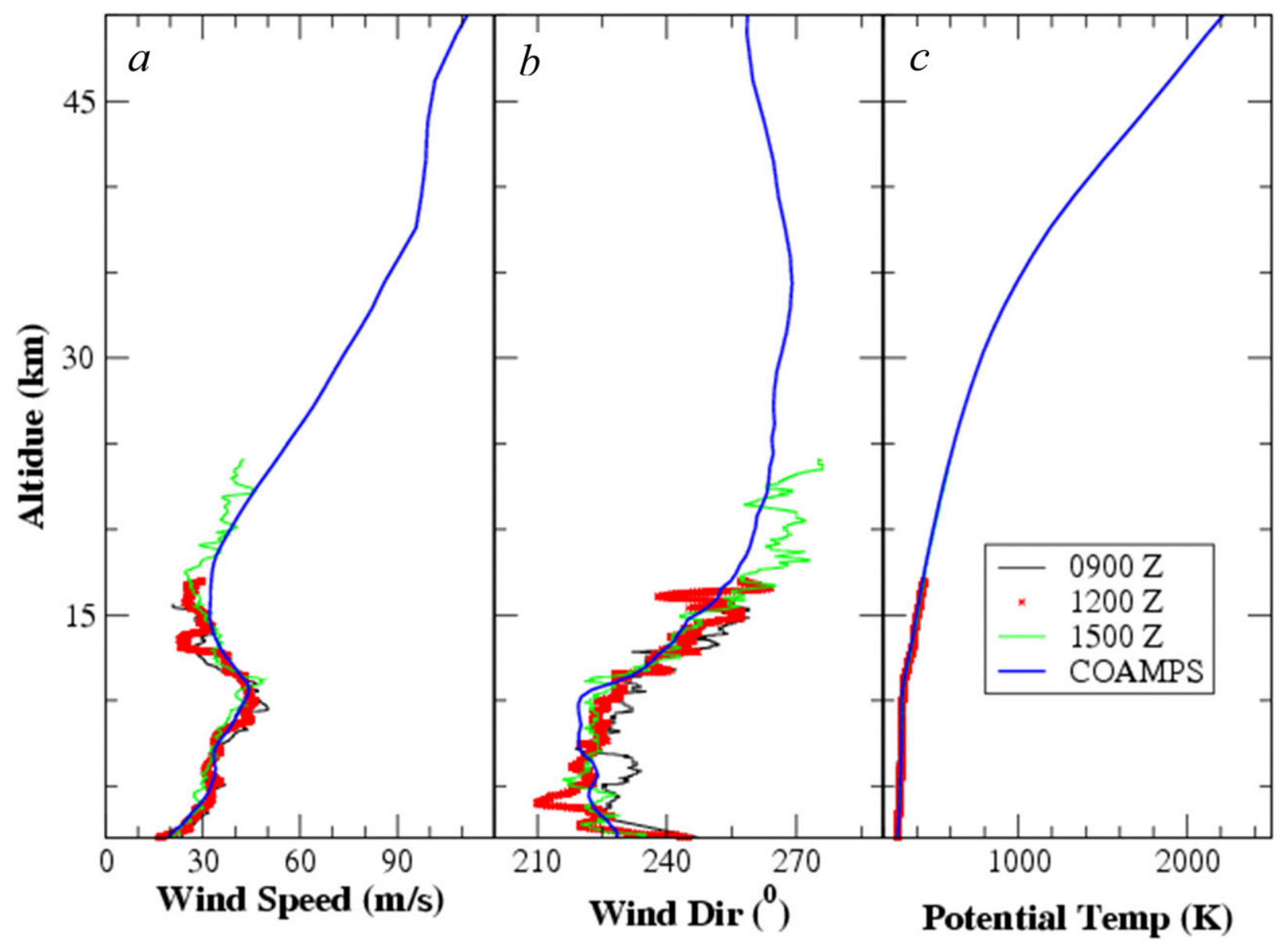

FIG. 6. Profiles of (a) wind speed $\left(\mathrm{m} \mathrm{s}^{-1}\right)$, (b) wind direction $\left(^{\circ}\right)$, and (c) potential temperature (K) from the Lauder radiosondes launched at 0900, 1200, and 1500 UTC 19 Jun 2014. The corresponding profiles from the COAMPS control simulation valid at 1200 UTC 19 Jun 2014 (blue) are included for comparison.

downstream propagation of trailing-wave activity. In the middle stratosphere and above (Figs. 9c and 9d), this southeastward extension of negative momentum flux intensifies in accordance with the STW beams in Figs. 4c, 4d, and 7d. While the primary maximum shifts slightly eastward, two more maxima appear $\sim 400 \mathrm{~km}$ to the east and $\sim 1500 \mathrm{~km}$ to the southeast of NZ, respectively. The corresponding vertical fluxes of meridional momentum and energy (not shown) are characterized by similar horizontal patterns and vertical variations, except that, while the meridional momentum flux is negative, the energy flux is positive, indicative of upward wave energy propagation.

Figure 10 shows vertical profiles of the fluxes between 6- and $45-\mathrm{km}$ altitude for IOP 6 , averaged over the horizontal areas plotted in Fig. 7. Both the zonal and meridional momentum fluxes are negative, associated with southwesterlies in the troposphere. In general, the magnitude of the momentum fluxes is much larger in the troposphere and decreases rapidly in the UTLS
( $40 \%-50 \%$ decrease between 10 and $20 \mathrm{~km}$ ), a layer characterized by significant directional wind shear (Fig. 6). The filtering effect on stratospheric waves of directional shear has been emphasized in previous studies as well (e.g., Eckermann et al. 2007; Krisch et al. 2017). The meridional flux is larger than its zonal counterpart in the troposphere and is smaller in the stratosphere, where the winds are close to westerly. According to linear wave theory, the momentum fluxes associated with steady gravity waves should be constant with height in the absence of critical-level absorption, wave breaking, or other nonlinear dissipative processes (Eliassen and Palm 1961). The vertical flux of wave energy is positive and exhibits a substantial decrease between 10 and $20 \mathrm{~km}$, consistent with the momentum flux profiles. It is interesting that the vertical energy flux actually increases between 20 and $30 \mathrm{~km}$, implying energy extraction from the ambient flow by gravity waves, associated with positive vertical wind shear. Also shown in Fig. 10 is the profile of $-\rho_{a}\left(U \overline{u^{\prime} w^{\prime}}+V \overline{v^{\prime} w^{\prime}}\right)$, which, according to 

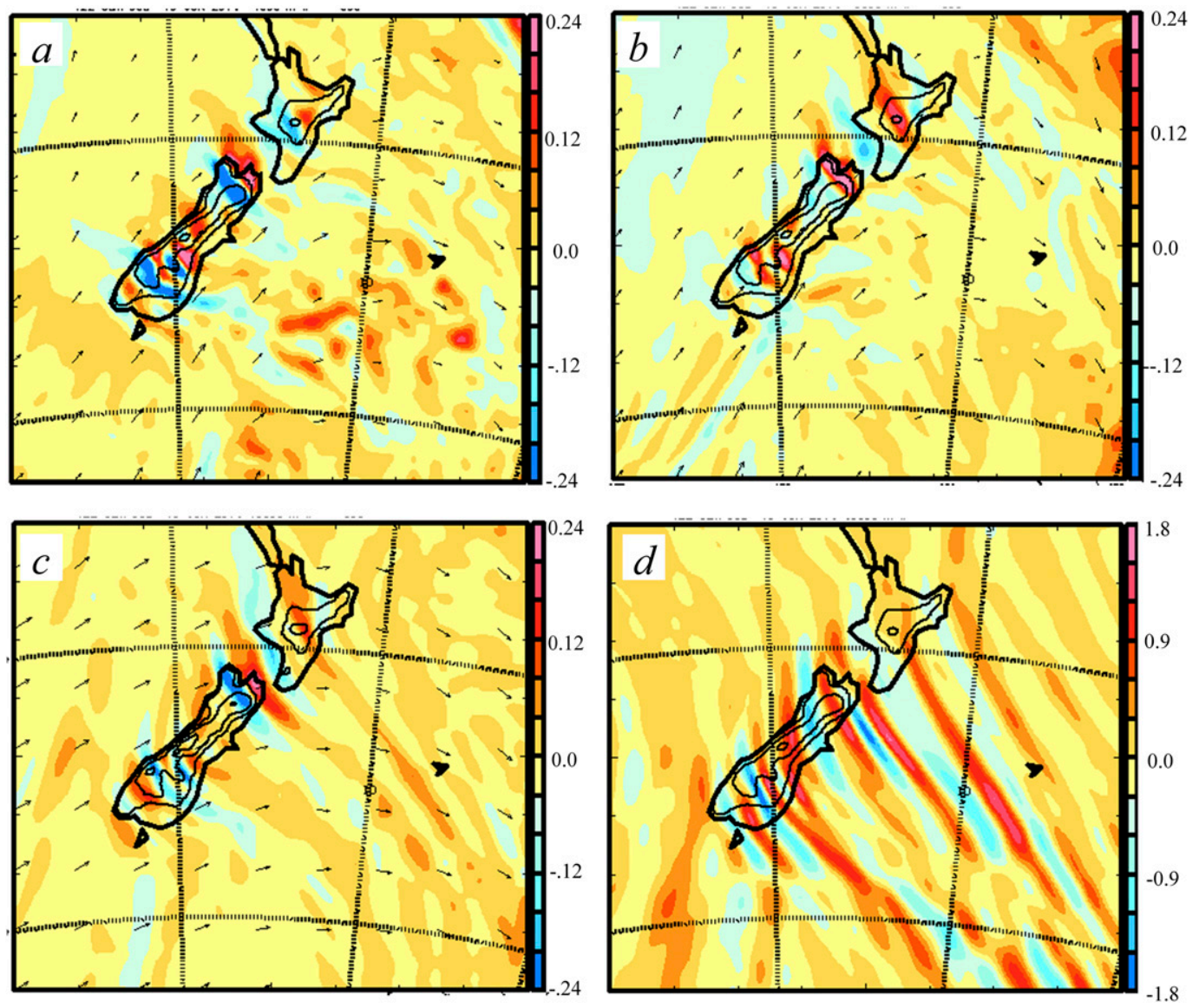

FIG. 7. Plan views of $w$ (color shading) and wind vectors at (a) $4 \mathrm{~km}$ (interval: $0.05 \mathrm{~m} \mathrm{~s}^{-1}$ ), (b) $9 \mathrm{~km}$ (interval: $0.02 \mathrm{~m} \mathrm{~s}^{-1}$ ), (c) $15 \mathrm{~km}$ (interval: $0.04 \mathrm{~m} \mathrm{~s}^{-1}$ ), and (d) $25 \mathrm{~km}$ (interval: $0.06 \mathrm{~m} \mathrm{~s}^{-1}$ ) MSL, derived from the control simulation of IOP 6 valid at 1200 UTC 19 Jun 2014. Terrain between 100 and $1300 \mathrm{~m}$ is shown in contours (interval: $600 \mathrm{~m}$ ). Only a subdomain around NZ and trailing waves from the $12-\mathrm{km}$ grid are shown.

the Eliassen and Palm theorem, should be equal to the vertical wave energy flux for linear stationary MWs. There are noticeable differences between the two energy flux terms below $\sim 15 \mathrm{~km}$, suggestive of contributions from nonstationary (likely nonorographic) waves or synoptic processes in the troposphere. The two energy terms track very well in the stratosphere in Fig. 10, suggesting that the dominant contribution in the stratosphere comes from steady quasi-linear MWs. The horizontal wave energy fluxes are shown in Fig. 10c. Both the zonal and meridional fluxes are negative, implying that the mean wave energy vector points into the ambient wind in the troposphere, which is balanced by mean-flow advection. In the stratosphere, both energy flux components are substantially smaller, in accordance with the decrease in the vertical momentum and energy fluxes.

In summary, the simulated STWs are vertically coherent steady waves for IOP 6 . In the troposphere, the waves are largely confined directly over NZ, and take on more parabolic shapes above the tropopause with their vertices aligned along the ridge axis, resembling classical hydrostatic wave solutions over an isolated peak (Smith 1980). The momentum fluxes are largely localized with a maximum directly over the Southern Alps. Strong asymmetry develops in the stratosphere, where the meridional shear of the zonal winds is pronounced, with the southern wave beams extending southeastward and forming STWs. The wave momentum (energy) fluxes are spread along these STW beams. While the magnitude of wave momentum fluxes is reduced sizably across the tropopause, the variation of the wave momentum and energy fluxes with height is broadly consistent with the Eliassen-Palm theorem in the stratosphere.

\section{Terrain and low-level wind effect}

Broadly speaking, the formation of stratospheric STWs can be attributed to two processes: namely, wave generation and propagation. The orographic wave generation is examined in this section with emphasis on the 

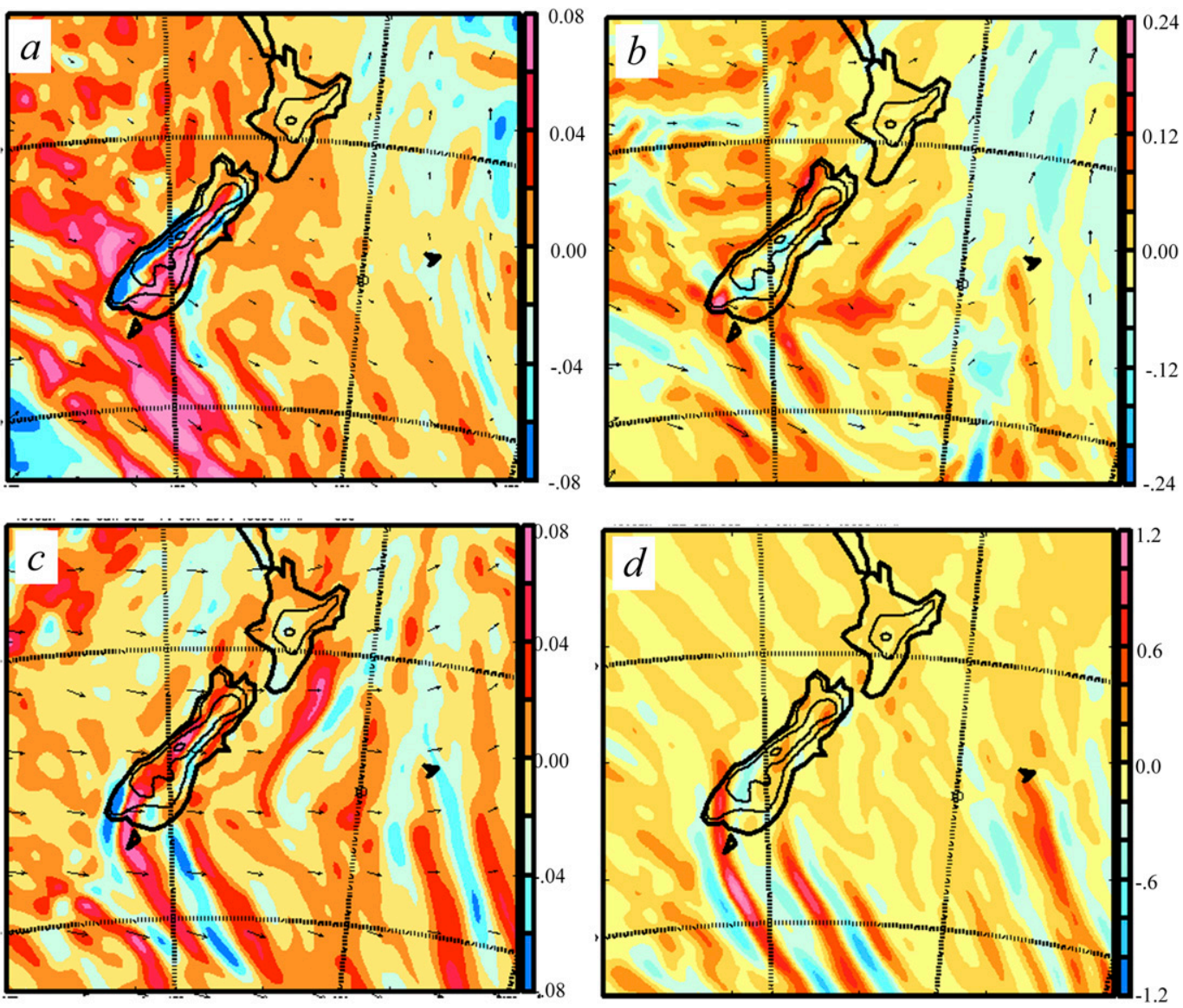

FIG. 8. Plan-views of $w$ (color shading) and wind vectors at (a) $4 \mathrm{~km}$ (interval: $0.02 \mathrm{~m} \mathrm{~s}^{-1}$ ), (b) $9 \mathrm{~km}$ (interval: $0.04 \mathrm{~m} \mathrm{~s}^{-1}$ ), (c) $15 \mathrm{~km}$ (interval: $0.01 \mathrm{~m} \mathrm{~s}^{-1}$ ), and (d) $25 \mathrm{~km}$ (interval: $0.02 \mathrm{~m} \mathrm{~s}^{-1}$ ) MSL, derived from the control simulation of IOP 3 valid at 1200 UTC 14 Jun 2014. Terrain between 100 and $1300 \mathrm{~m}$ is shown in contours (interval: $600 \mathrm{~m})$. The subdomain is as in Fig. 7.

sensitivity of STW characteristics to terrain and lowlevel winds, based on a set of five terrain sensitivity simulations and spectral analysis.

\section{a. Terrain sensitivity of trailing waves}

Orographic waves are generated by the interaction between topography and low-level winds. To shed light on the role that terrain plays in STW formation, we have carried out an additional set of five sensitivity simulations. The model configurations for these simulations are identical to the control run of IOP 6 except that the $\mathrm{NZ}$ terrain is replaced with modified or idealized terrain. These simulations include a no-terrain (NOTRN; terrain height over the New Zealand is set to $0.1 \mathrm{~m}$ with the nonzero elevation used to distinguish land and water surfaces), a half-terrain (HFTRN; i.e., the terrain height is reduced to half of the true terrain height), a smooth ridge (RIDGE), and two idealized multiple peak (i.e., PEAK1 and PEAK2) simulations. The idealized terrain height in the last three simulations takes the analytical form

$$
h\left(x^{\prime}, y^{\prime}\right)=\frac{h_{m} \cos ^{2}\left(2 \pi y^{\prime} / L_{y}\right)}{\left[1+\left(x^{\prime} / a\right)^{2}+\left(y^{\prime} / b\right)^{2}\right]^{3 / 2}},
$$

where $\left(x^{\prime}, y^{\prime}\right)$ denote the rotated coordinates

$$
\begin{aligned}
& x^{\prime}=x \cos \left(\alpha_{0}\right)+y \sin \left(\alpha_{0}\right), \\
& y^{\prime}=-x \cos \left(\alpha_{0}\right)+y \sin \left(\alpha_{0}\right) .
\end{aligned}
$$

In Eqs. (3) and (4), $h_{m}=3500 \mathrm{~m}$ is the maximum ridge height, $a=700 \mathrm{~km}$ is the main ridge length, $b=150 \mathrm{~km}$ is the ridge width, and $\alpha_{0}=-36^{\circ}$ is the tilting angle of the ridge with respect to the zonal direction. These parameters are chosen based on the real NZ terrain profile. In Eq. (3), the cosine-squared term represents smallerscale variations along the main ridge. The length-scale parameter $L_{y}=\infty$ (i.e., no small-scale variation), 400 , 

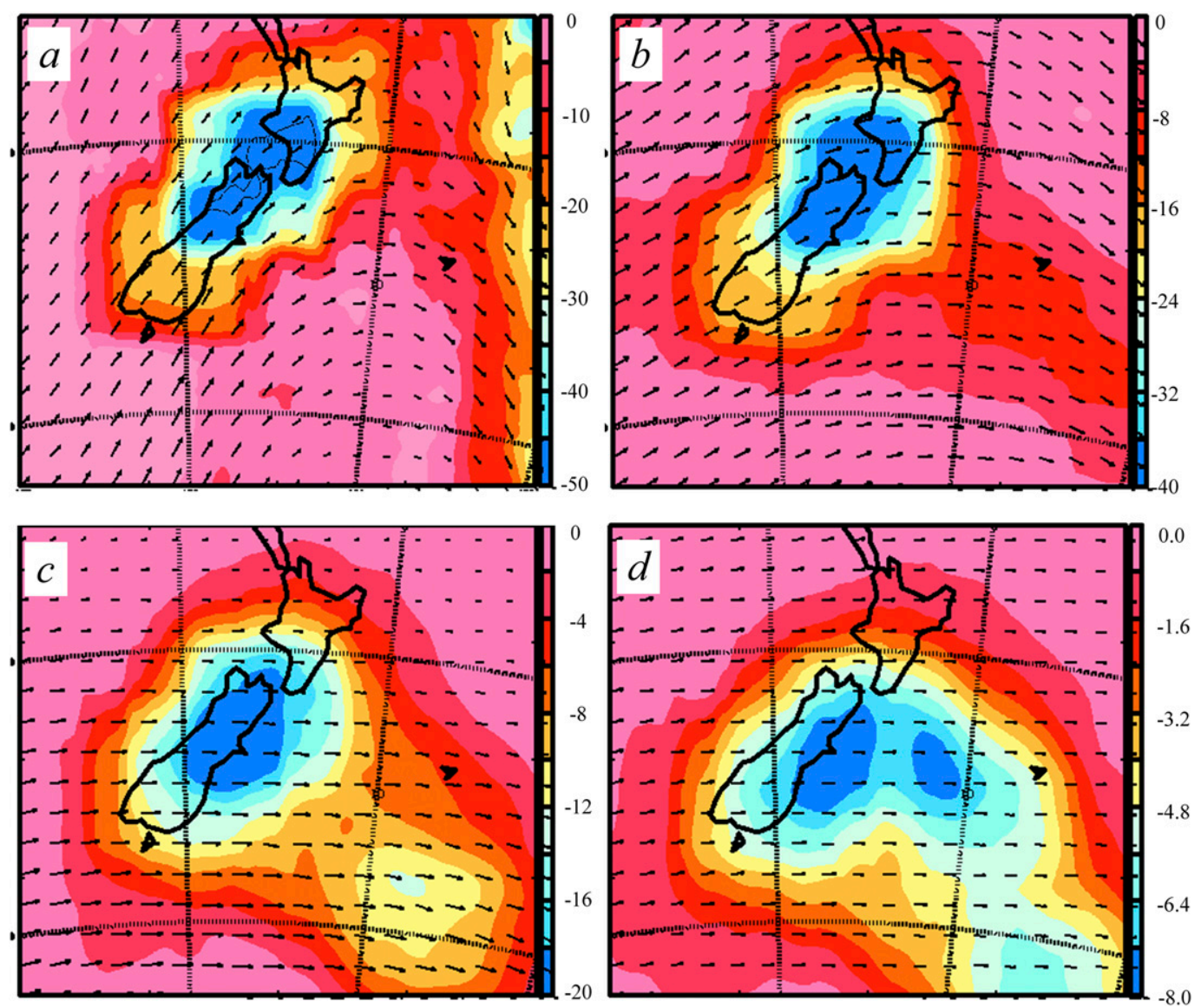

FIG. 9. Plan views of vertical fluxes of zonal momentum ( $\bar{\rho} \overline{u^{\prime} w^{\prime}}$; color shading) and wind vectors valid at 1200 UTC 19 Jun 2014, at (a) $9 \mathrm{~km}$ (interval: $5 \mathrm{mPa}$ ), (b) $15 \mathrm{~km}$ (interval: $4 \mathrm{mPa}$ ), (c) $25 \mathrm{~km}$ (interval: $2 \mathrm{mPa}$ ), and (d) $45 \mathrm{~km}$ MSL (interval: $0.8 \mathrm{mPa}$ ).

and $200 \mathrm{~km}$, for the RIDGE, PEAK1, and PEAK2 simulations, respectively (see black contours in Fig. 11), leading to a greater number of narrower peaks in PEAK2 (i.e., 7) than in PEAK1 (i.e., 3).

We first compare the wave patterns at $45 \mathrm{~km}$ MSL from HFTRN and NOTRN to the corresponding fields from the CNTRL simulation shown in Fig. 7. In the absence of the NZ terrain (i.e., NOTRN run), no distinguishable trailing waves are observed over or in the lee of NZ (not shown). The trailing-wave (TW) patterns in the HFTRN simulations (Fig. 11a) are nearly identical to those in the control except that the amplitude of the vertical velocity is much reduced. These simulations confirm, not surprisingly, that the simulated STWs over NZ are indeed orographically generated, with wave amplitude increasing with terrain height. Replacing the real terrain with RIDGE results in fewer and weaker trailing waves with noticeably wider spaces between adjacent wave beams (Fig. 11b) relative to CNTRL. For PEAK1 and PEAK2, the STWs are substantially stronger than those in the other simulations (Figs. 11c,d).
With narrower terrain peaks, PEAK2 results in stronger and more trailing-wave beams with shorter horizontal wavelengths $(\sim 100 \mathrm{~km}$ as opposed to $\sim 200 \mathrm{~km}$ for PEAK1). In addition, there is an approximate $10^{\circ}$ difference in the TW beam orientation between PEAK1 and PEAK2. Nevertheless, STWs are present in all these simulations (except for NOTRN) and exhibit strong leftright asymmetry with respect to the main ridge axis, with elongated wave beams confined to the southeast side of the terrain and much more restricted wave activity to the northwest side.

The vertical profiles of wave energy fluxes $E_{z}$ averaged over the same subdomain as in Figs. 7 and 8, valid at 1200 UTC 19 June 2014, are shown in Fig. 12 for the altitude between 10 and $45 \mathrm{~km}$, derived from the CNTRL, RIDGE, PEAK1, and PEAK2 simulations, with the corresponding $E_{z}^{*}=-\overline{\rho_{a}}\left(U \overline{u^{\prime} w^{\prime}}+V \overline{v^{\prime} w^{\prime}}\right)$ included as dashed curves. It is evident that the energy fluxes from the CNTRL and RIDGE simulations are much smaller than those from PEAK1 and PEAK2, and that the variations of momentum and energy fluxes with 


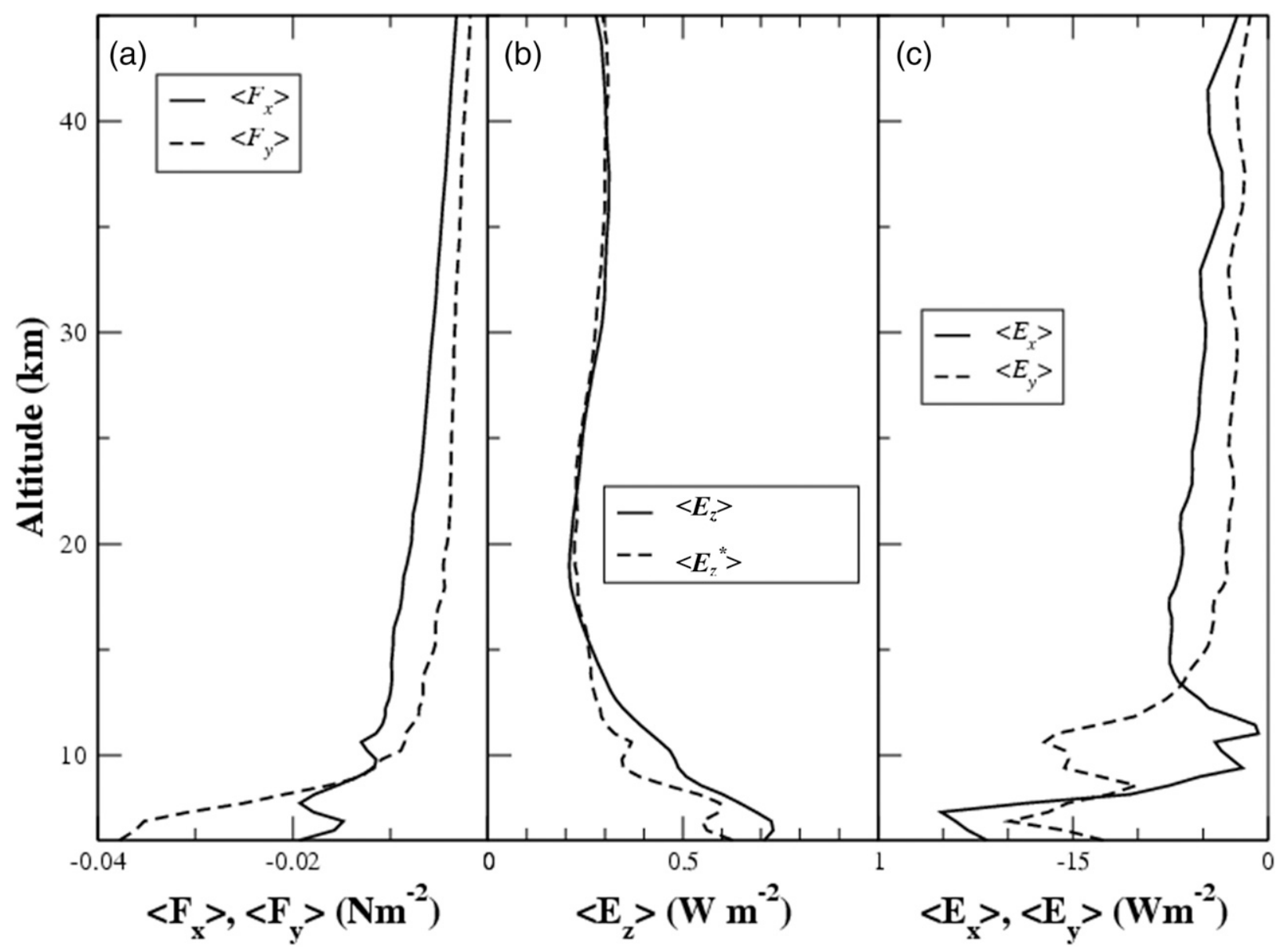

FIG. 10. Profiles of (a) vertical fluxes of zonal (solid) and meridional (dashed) momentum, (b) vertical wave energy flux (solid), and (c) horizontal energy fluxes in the zonal (solid) and meridional (dashed) directions, between 6 and $45 \mathrm{~km}$ and valid at $1200 \mathrm{UTC}$ 19 Jun 2014 (i.e., IOP 6). In (b), the profile of $\left\langle E_{z}^{*}\right\rangle=-\left\langle\bar{\rho}_{a}\left(U F_{x}+V F_{y}\right)\right\rangle$ is shown as the dashed curve. The angle brackets here denote horizontal averages over the subdomain shown in Figs. 7 and 8.

height is consistent with the Eliassen and Palm theorem. For PEAK1 and PEAK2, the energy flux $E_{z}$ is larger than $E_{z}^{*}$ between 10 and $20 \mathrm{~km}$, presumably associated with strong nonlinearity in these two simulations.

In summary, the terrain sensitivity simulations support the finding that the STWs over and downstream of NZ are of orographic origin and suggest that these waves are sensitive to terrain features. Some STW characteristics, such as the dominant wavelength and the number of and orientation of wave fronts, are largely controlled by the terrain. On the other hand, the most salient feature of trailing waves, namely the strong north-south asymmetry with long wave beams extending southeastward in the stratosphere, appears in all simulations except for NOTRN, which implies that the atmospheric environment plays a key role in modulating these stratospheric trailing waves.

\section{b. Terrain and low-level wind interaction}

The spectra of perturbation fields such as the vertical velocity near the wave source provide useful information about the distribution of perturbation energy over scales and wave vectors. Applying the linearized impermeable boundary condition at the terrain surface, the terrain-induced vertical motion can be written as

$$
\left.w(x, y, z)\right|_{z=0}=\mathbf{V} \cdot \nabla h,
$$

where $h=h(x, y)$ is the terrain profile. For practical purposes, the mountaintop winds are often used as an approximation of low-level winds. The nearly proportional relationship between wave fluxes aloft and the cross-mountain wind speed at the mountaintop level has been confirmed by a number of field observations (e.g., Smith et al. 2002; Doyle and Jiang 2006). For a given terrain profile and a horizontally uniform wind, $\mathbf{V}=(U, V)$, the vertical velocity in the wavenumber space $\hat{w}$ can be 

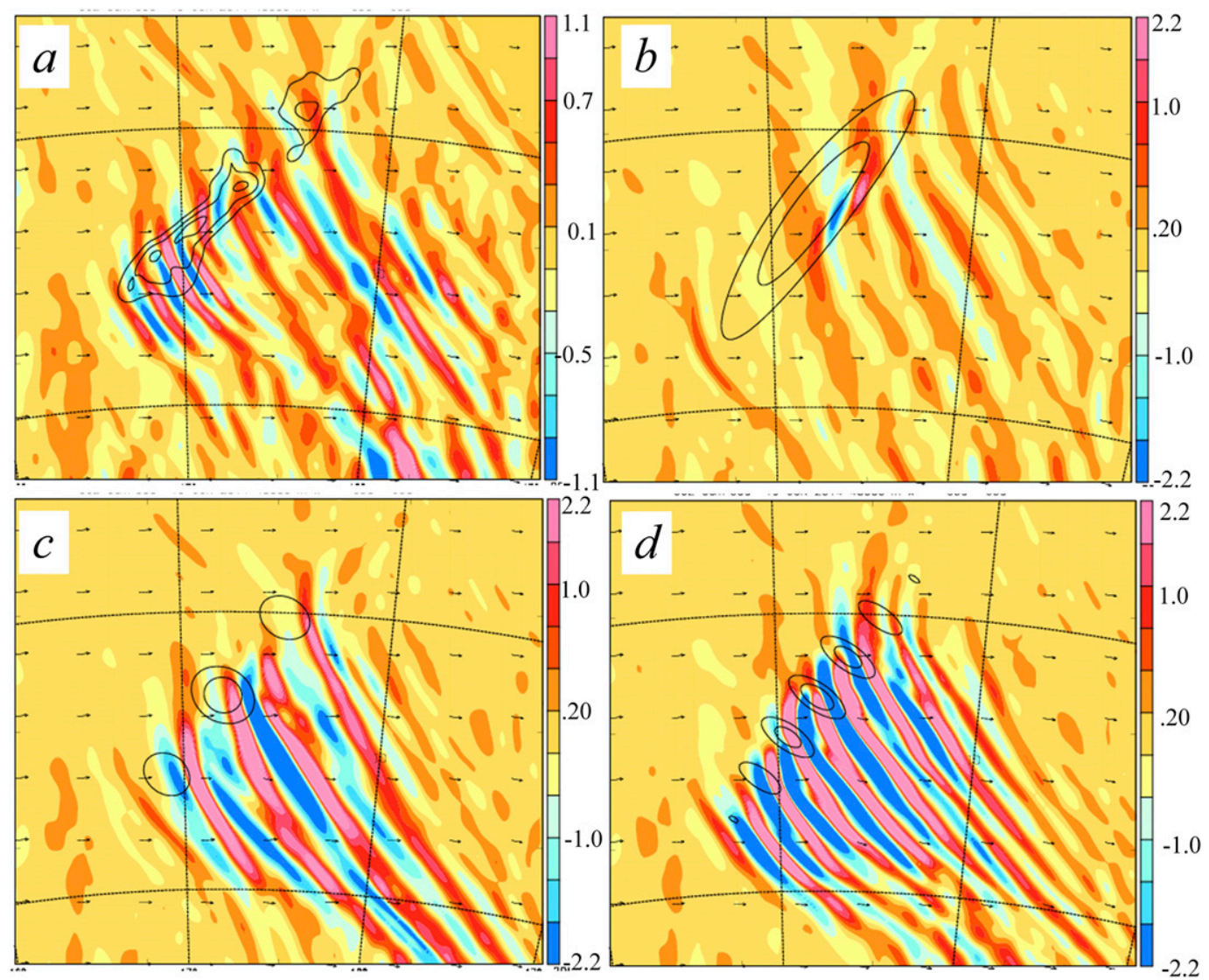

FIG. 11. The vertical velocity (color shading) and wind vectors at $45 \mathrm{~km}$ valid at 1200 UTC 19 Jun 2014, derived from four terrain sensitivity simulations: (a) HFTRN (interval: $0.2 \mathrm{~m} \mathrm{~s}^{-1}$ ), (b) RIDGE (interval: $0.4 \mathrm{~m} \mathrm{~s}^{-1}$ ), (c) PEAK1 (interval: $0.4 \mathrm{~m} \mathrm{~s}^{-1}$ ), and (d) PEAK2 (interval: $0.4 \mathrm{~m} \mathrm{~s}^{-1}$ ). The subdomain is as in Figs. 7 and 8 , and the terrain contours correspond to elevations of 100,600 , and $1200 \mathrm{~m}$.

conveniently obtained by performing two-dimensional Fourier transform on the right-hand side of Eq. (5):

$$
\hat{w}(k, l)=i(U k+V l) \hat{h}
$$

where $\hat{h}$ is the terrain spectrum and $(k, l)$ denotes the zonal and meridional wavenumber pair. The power spectra of $w$, $\hat{P}=\hat{w} \hat{w}^{*}$, where $\hat{w}^{*}$ denotes the complex conjugate of $\hat{w}$, are shown in Fig. 13, as a proxy of the perturbation energy near the wave source. Figures 13a-c display the normalized $w$ spectra using the same terrain profile as used in the COAMPS 12-km grid in the CNTRL simulation and three different mountaintop wind directions, namely, (Fig. 13a) SSW $\left(245^{\circ}\right.$, the angle relative to the east), (Fig. 13) westnorthwesterly (WNW; 205 ), and (Fig. 13c) NW (135 ). The dotted circles correspond to the total horizontal wavenumbers, $K=\sqrt{k^{2}+l^{2}}$, of $2 \pi / 100$ and $2 \pi / 200 \mathrm{~km}^{-1}$, respectively. It is evident that the perturbation energy can project onto all directions and a wide range of length scales but the precise partitioning varies substantially with the upstream wind direction.
These forced perturbations are subject to the atmospheric filtering as they propagate away from the terrain, so only a fraction of this perturbation energy is able to propagate into the stratosphere and contribute to STW formation. Examples of these filtering processes are depicted schematically in Fig. 13. First, for steady MWs, the intrinsic frequency $\Omega=-\mathbf{V} \cdot \mathbf{K}=-(U k+l V)$ should be greater than zero, corresponding to waves propagating against the mean winds. Therefore, only perturbations with wavenumbers located to left of the dashed line $\mathrm{AA}^{\prime}$, which is perpendicular to the ambient winds (i.e., $\Omega=-\mathbf{V} \cdot \mathbf{K}=0$ along $\mathrm{AA}^{\prime}$ ), are considered here. Second, as waves propagate through a directional shear layer, they continuously encounter critical levels where $\Omega=U k+l V$ becomes zero and these wave modes are absorbed. According to Fig. 6a, substantial directional shear exists in the UTLS (i.e., $\sim 10-20 \mathrm{~km}$ ) during IOP 6 , above which the winds are primarily westerly. The dash-dotted line $\mathrm{BB}^{\prime}$ corresponds to $\Omega=0$ for westerlies. In Fig. 13a, the wave modes in the fourth quadrant between $\mathrm{AA}^{\prime}$ and $\mathrm{BB}^{\prime}$ are subject to critical-level 


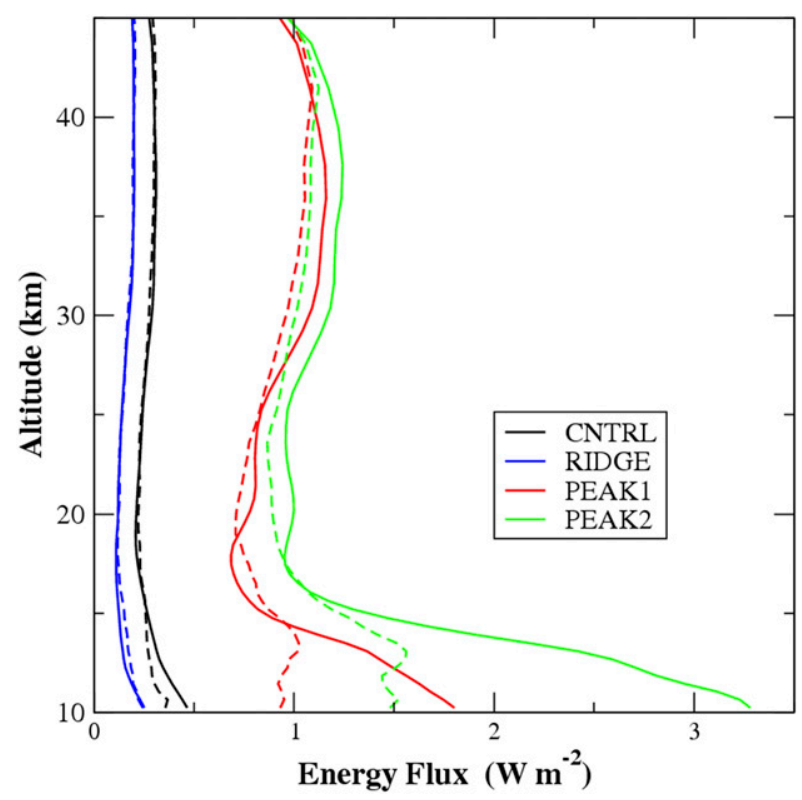

FIG. 12. The profiles of vertical wave energy flux $E_{z}$ derived from four simulations: CNTRL RIDGE, PEAK1, and PEAK2. The fluxes are averaged over the trailing-wave subdomain shown in Figs. 7 and 8 . The corresponding profiles of $E_{z}^{*}=-\left(U F_{x}+V F_{y}\right)$ (dashed lines) are included for comparison.

absorption as the wind direction turns from SSW to westerlies aloft. Another necessary condition for a wave to propagate vertically is that $\Omega^{2}-f^{2}>0$, where $f$ is the Coriolis parameter. A wave is either absorbed or reflected when encountering a layer where $|\Omega|=|f|$, which is often referred to as a Jones critical level (Jones 1967; Kitchen and McIntyre 1980). This condition can be written as $|\mathbf{V}| K \cos (\alpha)>|f|$, where $0^{\circ}<\alpha<90^{\circ}$ is the angle between the wave vector and the wind direction at a given level. Accordingly, we can define a cutoff wavenumber as $K_{\text {cutoff }}=|f| /[|\mathbf{V}| \cos (\alpha)]$, and below this, threshold waves would be absorbed. The variation of the cutoff wavenumber with wave vector angle is schematically shown in Fig. 13 as the thin dashed curve $\mathrm{C}$ and only those modes with wave vectors located to the left side of the $\mathrm{C}$ curve can propagate into the stratosphere.

In Fig. 13a, the mountaintop wind is from the SSW, and the $w$ spectrum is characterized by two maxima in the inner circle (i.e., horizontal wavelengths longer than $200 \mathrm{~km}$ ) and to the lower left of curve C. The two maxima correspond to the northeastward (labeled " 1 ", with $k<0$ and $l>0$ ) and southeastward (labeled "2" with $k<0$ and $l<0$ )-oriented wave beams, respectively. The maximum in the fourth quadrant (labeled as " 3 ") may exist in the troposphere but could not enter into the stratosphere because of critical-level absorption. It is worth noting that the STW vectors for IOP 6 estimated from Figs. 4 and $7 d$ are approximately oriented along maximum 2 in Fig. 13a. When the low-level ambient wind is WSW, there are two maximum lobes located to the left of the dashed curve $\mathrm{C}$, corresponding to waves that may enter the stratosphere (Fig. 13b). More perturbation energy is projected onto maximum 1 (i.e., the northeast-oriented waves) and a much smaller fraction onto maximum 2 (i.e., potential STWs), suggesting that likely STWs become weaker as the mountaintop wind direction changes from SSW to WSW given all other conditions the same. Finally, if the ambient winds are northwesterlies such as in IOP 3 , there are two maxima located to the upper left of the C curve (Fig. 13c). The wave vectors of the primary maximum are oriented in the opposite direction of the mountaintop wind, corresponding to the ridge-parallel waves in Fig. 8, and the wave vectors associated with maximum 2 are related to STWs.

Also shown in Fig. 13 are the $w$ power spectra using the idealized terrain in RIDGE, PEAK1, and PEAK2 for SSW winds. Over a smooth ridge, most perturbation energy is confined in the inner circle with horizontal wavelengths larger than $200 \mathrm{~km}$. Only a minor maximum is present to the lower left of curve C, likely associated with the southern ridge tip (Fig. 13d). Accordingly, the trailing waves are very weak in the RIDGE simulation. For PEAK1, perturbations forced by flow over individual peaks dominate, and the primary maxima are located outside of the inner circle (Fig. 13e). The center of the maximum corresponds to a wavelength of roughly $180 \mathrm{~km}$, which is consistent with the trailing waves in the PEAK1 simulation in Fig. 11c. Only a small fraction of energy is projected onto quadrant 2 , and consequently, waves in PEAK 1 exhibit strong north-south asymmetry. For PEAK2, the primary maxima are centered approximately at $K=2 \pi / 93 \mathrm{~km}^{-1}$, corresponding to a substantially shorter wavelength than in PEAK1. In addition, the wavenumber ratio $|l / k|$ along the maximum is larger than in PEAK1, implying that the trailing-wave phase lines in PEAK2 should have a smaller angle from the zonal direction, which is consistent with the simulations (Figs. 11c,d).

There are a few caveats in this analysis that are worth mentioning. First, wave refraction associated with horizontal wind shear is not considered here and will be addressed in the next section based on ray-path calculations. Second, the energy spectra vary with the model grid spacing, and more perturbation energy is likely projected onto smaller scales if the model grid spacing is finer, although those smaller-scale waves are beyond the scope of this study. Finally, nonlinear processes such as upstream blocking, flow splitting (Smith et al. 2002), and boundary layer adjustment (Jiang et al. 2008) may play an important role in MW generation and are not taken into account in Eq. (5). Still, we believe the above linear analysis 

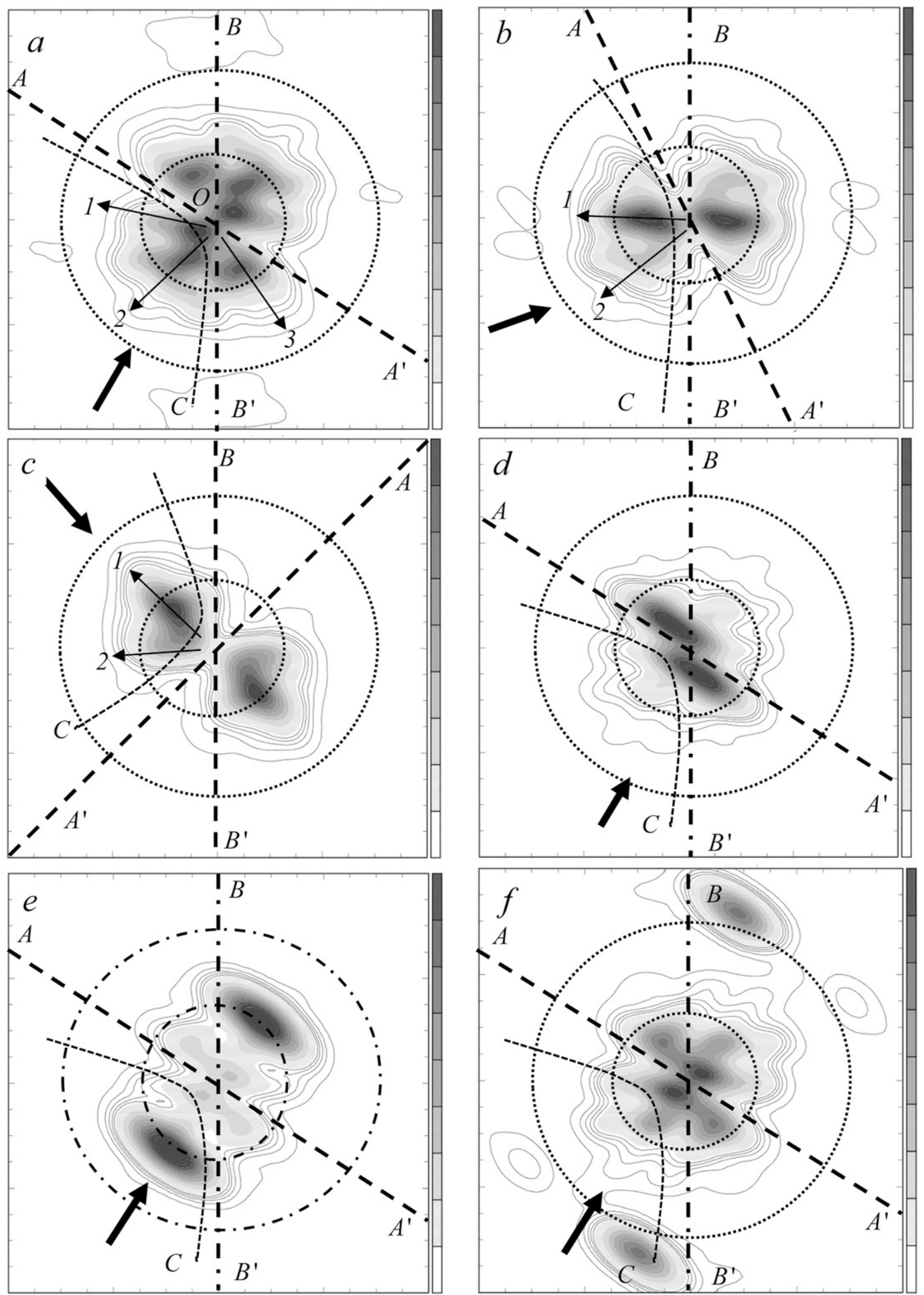

FIG. 13. (a)-(c) The normalized vertical velocity spectra (grayscale, from 0.1 to 1 and increment $=0.1$; contours, from 0.01 to 0.1 , interval: 0.01 ) derived from the linear lower boundary condition in Eq. (5) using $15-\mathrm{km} \mathrm{NZ}$ terrain and hypothetical wind directions. The wind directions are (a) south-southwesterlies $\left(245^{\circ}\right.$ from east), (b) westsouthwesterlies $\left(215^{\circ}\right)$, and (c) northwesterlies $\left(135^{\circ}\right)$. (d)-(f) The spectra of $w$ from the interaction between SSW and idealized topography for RIDGE, PEAK1, and PEAK2, respectively. Bold arrows represent mountaintop wind directions; dashed lines $\mathrm{AA}^{\prime}$ and dash-dotted lines $\mathrm{BB}^{\prime}$ correspond to the $\Omega$-critical levels at the mountaintop level and above UTLS, respectively; the two dashed circles correspond to two reference wavenumbers, $2 \pi / 100$ and $2 \pi / 200 \mathrm{~km}^{-1}$; and dashed curve $\mathrm{C}$ corresponds to the Jones critical level. The thin arrows in (a) and (c) correspond to the wavenumber vectors estimated from IOP 6 and 3 simulations, respectively. 
is relevant for the following reasons. The purpose of the analysis is to understand the qualitative variation of two-dimensional wave spectra (not the wave amplitudes) to low-level winds and terrain interaction. According to Smith et al. (2002), in the presence of upstream blocking and/or airflow spitting over high hills, linear wave theory is still applicable after replacing the real terrain with an effective terrain profile $h_{\text {eff }}=h-h_{\text {cutoff }}$, where $h_{\text {cutoff }}$ represents the blocked layer depth (Eckermann et al. 2010). Physically, this approach implies that only terrain above the blocked (or flow splitting) layer contributes to wave generation. For the NZ terrain profile, the use of $h_{\text {eff }}$ in Eq. (5) has relatively insignificant impact on the normalized STW spectra (i.e., waves with wavelength between 100 and $600 \mathrm{~km}$ ) and has likely more substantial impact on longer waves. Nevertheless, this simple spectral analysis is in qualitative agreement with the nonlinear COAMPS simulations and provides useful insights into the dependence of the STW characteristics (i.e., wavelength, wave phase-line orientation, and wave amplitude) on terrain characteristics and low-level wind direction.

\section{Wave refraction and ray-tracing calculations}

In addition to critical-level absorption, gravity waves are subject to reflection, refraction, instability, and breakdown associated with vertical or lateral wind shears and sharp stratification variations when propagating through a deep atmosphere. In this section, we aim to provide further insight into the possible role of a horizontal wind shear in shaping trailing waves through ray-path calculations using the simulated wind and buoyancy-frequency fields from IOP 6.

Each ray is launched from the location of the highest peak of the Southern Alps and $6 \mathrm{~km}$ MSL at 1200 UTC 18 June 2014. The ray path for a given wave packet is calculated by numerically integrating the spatial ray equations (see appendix) for $24 \mathrm{~h}$ with a time step $\Delta t=$ 5 min. The hourly COAMPS output of the horizontal winds $\mathbf{V}=(U, V)$ and horizontally averaged buoyancyfrequency $N(z)$ are linearly interpolated in time to each 5 -min increment for the calculation. A ray terminates before the end of the $24 \mathrm{~h}$ when reaching the $45-\mathrm{km}$ level or sidewalls. The initial horizontal wavenumber pair can be written as $\left(k_{0}, l_{0}\right)=K_{0} e^{i \theta_{0}}$, where the total wavenumber is $K_{0}=2 \pi / \lambda_{0}$ and the wave azimuth angle $\theta_{0}$ varies between $90^{\circ}$ and $270^{\circ}$.

Shown in Fig. 14 are four collections of ray group trajectories in the $y-z$ plane with the wave angle held constant in each case, while the wavelength $\lambda_{0}$ increases from 60 to $600 \mathrm{~km}$. Figure 14a shows a ray group trajectories for a wave angle $\theta_{0}=165^{\circ}$ (i.e., phase lines oriented northeastward $70^{\circ}$ from the east direction). The meridional group propagation distance (i.e., $y$ ) for a wave shorter than $200 \mathrm{~km}$ exhibits a moderate increase with height in the troposphere and across the UTLS associated with northward group velocity (i.e., $l>0$ and accordingly $C_{g y}>0$ ) and advection by the southerly wind component (i.e., $V>0$ ). Ray paths are close to vertical in the midstratosphere and above, where the meridional wind component is close to zero and the meridional wavenumbers become nearly zero because of lateral wave refraction. For longer waves, the ray path is more horizontal and the vertical group velocity becomes very slow as $\Omega$ approaches $\pm f$.

If the wave angle is $180^{\circ}$ (i.e., wave phase lines are north-south oriented and $l_{0}=0$ ), the ray paths exhibit moderate northward tilting in the troposphere, largely because of the positive meridional wind component (Fig. 14b). The ray paths of longer waves tend to propagate farther north owing to their slower vertical group velocity and therefore longer duration in the troposphere. Approximately at the level of the tropopause, the ray paths curve back toward the wave source (i.e., in the meridional direction), implying that the waves start propagating southward in response to directional shear (e.g., Eckermann et al. 2007). In the stratosphere, the northerly wind component reduces to nearly zero and the meridional wavenumber becomes negative because of lateral wave refraction associated with the negative meridional shear of the zonal wind. Consequently, waves propagate southward in the stratosphere.

If the initial wave angle is $210^{\circ}$ (i.e., in the third quadrant, corresponding to northwest-southeast-oriented STW fronts), the ray paths are nearly vertical in the troposphere, because of the partial cancelation between the northward advection by the southerly wind component and the southward propagation (Fig. 14c). In the upper troposphere and stratosphere, the ray paths tilt southward because of the weakening of the southerly wind component in conjunction with the increase of the southward group velocity component. The longer the wavelength, the more the ray path tilts southward.

Finally, for $\theta_{0}=240^{\circ}$ (i.e., SSW, STW example with the wave front oriented southeastward $30^{\circ}$ from the zonal direction), the southward propagation dominates and all ray paths tilt markedly southward with height (Fig. 14d). At a given level, the meridional distance of the ray path from the source is larger for a wave with a longer horizontal wavelength, which we attribute to a larger meridional-to-vertical group velocity ratio [i.e., $\left.\left|\left(V+C_{g y}\right) / C_{g z}\right|\right]$, also referred to as the meridional ray-path slope. For example, at $45 \mathrm{~km} \mathrm{MSL}$, for the wave packets with $\lambda_{0}=300$ and $400 \mathrm{~km}$, the meridional distances are approximately 600 and $800 \mathrm{~km}$, respectively. 

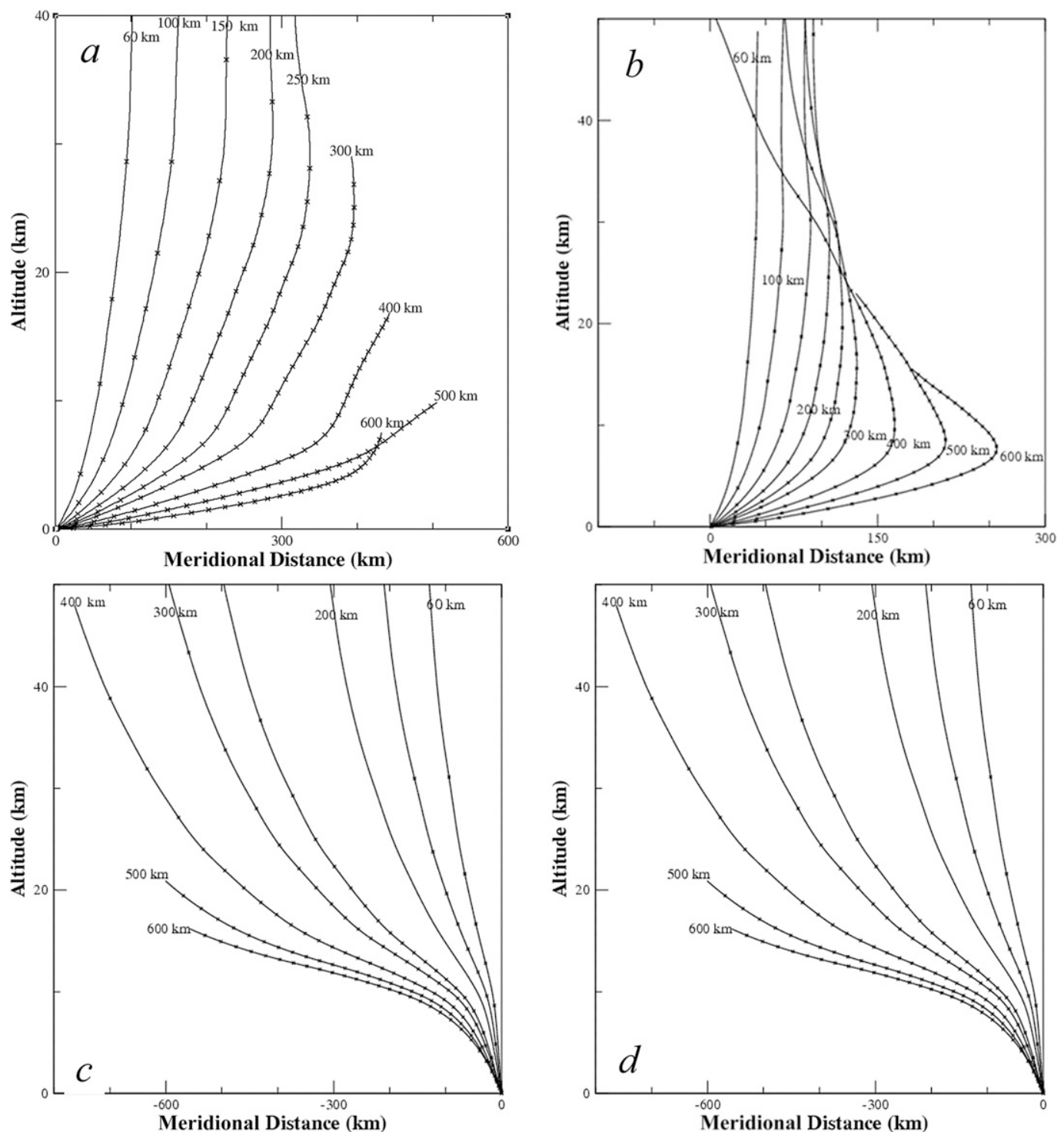

FIG. 14. The ray paths in the $y-z$ plane for four families of waves with initial horizontal wavenumbers given by $\mathbf{K}_{0}=\left(k_{0}, l_{0}\right)=K_{0}(\cos \theta, \sin \theta)$, where the phase angle is (a) $165^{\circ}$ (i.e., in the second quadrant), (b) $180^{\circ}$, (c) $210^{\circ}$ (in the third quadrant), and (d) $240^{\circ}$ (in the third quadrant), and the wavenumber magnitude, $K_{0}=2 \pi / \lambda_{0}$, varies with values of $\lambda_{0}=60,100,150,200,250,300,400,500$, and $600 \mathrm{~km}$.

On the other hand, for the examples shown in Fig. 14d, waves with wavelength longer than $500 \mathrm{~km}$ cannot reach the stratosphere within $24 \mathrm{~h}$ because of their slower vertical group velocity.

Several ray-path examples are shown in the $x-y$ plane in Fig. 15. The ray paths in these examples fall into one of the three categories: 1) approximately following a straight line, 2) curving back toward $y=0$, and 3) concave curving down and away from $y=0$. Category 1 includes waves shorter than $150 \mathrm{~km}$, and their ray path tends to follow a straight line, implying that $\left(V+C_{g y}\right) /\left(U+C_{g x}\right) \approx$ const, and the refraction effect is negligible. Category 2 includes waves with a wavelength $150 \mathrm{~km}$ or longer and with an initial wave angle $\theta_{0}=165^{\circ}$ or $180^{\circ}$. For this category, the initially northwardpropagating wave packet slows down or turns to southward propagating aloft, under the influence of refraction. Category 3 corresponds to STWs with paths curving away from $y=0$, implying that the ratio $\left|\left(V+C_{g y}\right) /\left(U+C_{g x}\right)\right|$ increases as waves propagate into the stratosphere, even though the zonal wind component increases as well.

In summary, the ray-path calculations at least generally explain the north-south asymmetry of STWs. For a wave source between $40^{\circ}$ and $60^{\circ} \mathrm{S}$, the northward 


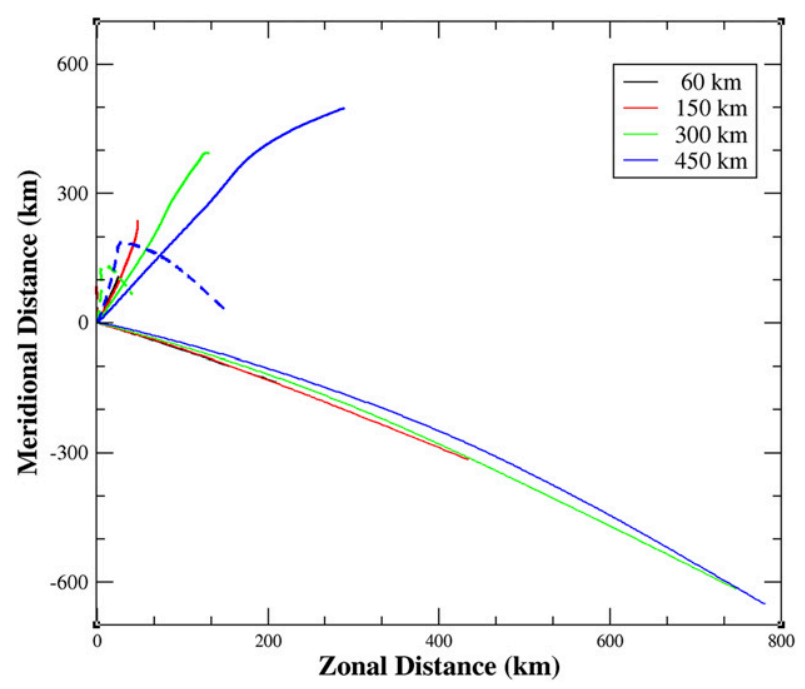

FIG. 15. The ray paths in the $x-y$ plane for three groups of solutions corresponding to wave angle $=165^{\circ}$ (thick solid), $180^{\circ}$ (thick dashed), and $240^{\circ}$ (thin solid) are plotted as color curves. For each phase angle, four paths are shown corresponding to wavelength $=60$ (black), 150 (red), 300 (green), and $450 \mathrm{~km}$ (blue).

extension of wave fronts tends to be shorter than that of its southern counterpart because of wave refraction associated with the negative meridional shear of the zonal wind in the stratosphere. This can be seen from Eq. (A3), with $k<0$ and $\partial U / \partial y<0$, which yields $d_{g} l / d t<0$ and increasing negative $l$ along ray paths with time. For southeast-oriented wave phase lines, $l<0$, and the shearinduced refraction increases the magnitude of the meridional wavenumber, which tends to increase the southward group velocity component and therefore favors the formation of long southeast-oriented wave beams in the stratosphere. For north- or northeast-oriented wave phase lines, $l>0$ in the troposphere, and wave refraction tends to decrease $l$ toward zero or to negative values and therefore shortens the north- or northeast-oriented wave beams.

\section{Discussion and concluding remarks}

STWs downstream of NZ topography have been examined by analyzing two STW events documented during DEEPWAVE field observations. For both events, the COAMPS-simulated stratospheric waves compare well with satellite and aircraft observations. Based on diagnosis of the COAMPS simulations, we conclude that these waves are orographically generated gravity waves with the following characteristics: (i) from a geographical perspective, STWs occur over terrain located to the south of approximately $40^{\circ} \mathrm{S}$, where strong and deep stratospheric westerlies are often present; (ii) the horizontal wavelength is roughly between 100 and $600 \mathrm{~km}$, one order of magnitude longer than typical tropospheric MWs (i.e., $\sim 10-50 \mathrm{~km}$ ); (iii) STWs usually are difficult to detect in the troposphere because of their typically small amplitudes and only become more apparent in the stratosphere; and (iv) STWs exhibit strong north-south asymmetry with the elongated quasi-linear wave phase lines extending as beams toward the westerly stratospheric jet core. These characteristics are directly tied to the STW formation mechanisms, such as low-level wind-terrain interaction, wave absorption and dissipation associated with directional shear, and refraction due to pronounced meridional shear in the stratospheric westerlies.

Broadly speaking, characteristics of STWs are determined by two processes: wave generation and propagation. The STW generation is largely controlled by terrain features and low-level winds, and the interaction between the two dictates the distribution of perturbation energy over horizontal scales and directions. High-latitude terrain such as the Southern Andes, the Antarctic Peninsula, and the Southern Alps are massive quasitwo-dimensional barriers, which project substantial perturbation energy onto scales larger than $600 \mathrm{~km}$ with relatively large $|k / l|$ ratios. However, for the reasons summarized below, these longer or more two-dimensional waves may have limited contributions to these STWs. Instead, individual peaks (e.g., Patagonia in the Southern Andes) and barrier tips, which project more energy onto wave modes with $|k / l| \sim 1$ and horizontal wavelengths between 100 and $600 \mathrm{~km}$, are likely more important STW generators. In addition, the perturbation energy spectra are found to be fairly sensitive to the low-level wind direction, which plays a role in regulating the STW wavelength and orientation. The difference between the low-level wind direction and the stratospheric westerlies also serves as a useful parameter for evaluating critical-level absorption, and a larger angle between the two implies that more wave modes are absorbed by encountering critical levels before entering the stratosphere. The directional shear filters out wave components in a certain range of wave angles and, accordingly, plays a role in STW mode selection.

The wavelengths of observed and numerically simulated STWs are approximately in the range of 100 $600 \mathrm{~km}$. The precise wavelength range may vary with a number of parameters, such as the atmospheric stratification, the relative position of the wave source and the stratospheric jet core, meridional wind shear, and tropospheric wind speed. Shorter waves (i.e., $\lambda<100 \mathrm{~km}$ ) have fast vertical group velocity and slower horizontal group velocity and, accordingly, tend to propagate more vertically. As a result, shorter waves are largely 
confined in the vicinity of the wave source, even in the stratosphere, and thus make little contribution to the STWs that extend thousands of kilometers from the terrain (e.g., Fig. 14d). Two conditions presumably set the upper limit on the STW horizontal wavelength. First, a necessary condition for a freely propagating gravity wave is $\omega^{2}-f^{2}>0$, which yields a maximum wavelength, $\lambda_{\text {cutoff }}=2 \pi|\mathbf{V}| \cos (\alpha) /|f|$, where $0<\alpha<90^{\circ}$ is the angle between the wave vector and the wind direction at a given level. Waves longer than this wavelength are subject to absorption at the level where $\Omega^{2}-f^{2}=0$, known as a Jones critical level. If this layer is adjacent to the ground, any perturbations with scales longer than $\lambda_{\text {cutoff }}$ cannot freely propagate deeply into the stratosphere. Second, because of slower vertical group velocity, some long waves cannot enter into the stratosphere in a reasonable time frame (e.g., $24 \mathrm{~h}$ or some other synoptic time scales). In addition, if the tropospheric jet above the wave source is too narrow, a long wave may propagate out of the tropospheric jet before entering the stratosphere.

A striking feature of STWs is their strong north-south asymmetry with impressive longwave beams extending southeastward (i.e., for southern Andes and New Zealand; northeastward for waves originated from the Antarctic Peninsula) and much shorter wave beams on the opposite side. This asymmetry is largely due to lateral wave refraction in the stratosphere where the meridional shear of the westerlies is pronounced. The meridional shear tends to stretch STW beams by increasing the group velocity in the meridional direction, and slows down the meridional propagation of waves on the opposite side. It is worth noting that the latitude of the wave source is crucial for wave refraction and, therefore, STW formation. Statistically, the stratospheric westerly jet maximum is centered at approximately $60^{\circ} \mathrm{S}$. If a wave source is located around $40^{\circ}-50^{\circ} \mathrm{S}$ (e.g., NZ terrain or Patagonia), where the meridional shear of the stratospheric westerlies is negative, STWs develop to the south of the wave source with wave fronts on the northern side largely confined in the vicinity of the terrain as shown for the cases examined in this study. If a wave source is located to the south of $60^{\circ} \mathrm{S}$ (e.g., the Antarctic Peninsula), where the meridional shear is positive in the stratosphere, trailing waves develop to the north of the terrain. If a wave source is located in the vicinity of the stratospheric westerly maximum, where $\partial U / \partial y \sim 0$ (e.g., South Georgia, $\sim 60.5^{\circ} \mathrm{S}$ ), wave refraction is insignificant in the vicinity of the source, and accordingly the stratospheric waves are more northsouth symmetric (Alexander et al. 2009).

Comparing wave momentum fluxes observed over mountains at or below the tropopause level from previous research flights [wavelength: $30-120 \mathrm{~km}$; momentum flux: $0.2-1 \mathrm{~Pa}$; see Table 5 of Smith et al. (2016)], the magnitude of the STW momentum flux in the midstratosphere for IOP 6 (Fig. 10) is at least one order of magnitude smaller. However, the momentum carried by long STWs could be dynamically important for general circulations in the stratosphere and mesosphere for the following reasons. First, STWs may be able to propagate deep into the stratosphere or even the mesosphere without breakdown, owing to their generally smaller wave amplitude in the troposphere and lower stratosphere, and their tendency to propagate toward stronger westerlies in the stratosphere. Second, unlike the momentum flux from shorter waves, which is largely confined in the vicinity of the wave source, the momentum flux from trailing waves may spread over a substantially larger area (e.g., more than $\sim 10^{\circ}$ latitude by $10^{\circ}$ longitude in Fig. 9). Therefore, a simple comparison between local momentum flux maxima (or leg-averaged flux from research flight in situ measurements) from shorter and longer waves may be misleading in terms of their net drag impacts. While trailing waves are usually much weaker in the troposphere than shorter mountain waves (i.e., wavelength $<100 \mathrm{~km}$ ), they may still carry an appreciable amount of total wave momentum (i.e., areaintegrated momentum fluxes) into the stratosphere. Last, although the momentum flux associated with trailing waves may spread over a large area of the stratosphere, their wave sources, those individual peaks in major barriers, are likely underresolved in general circulation and climate models. Therefore, widespread momentum fluxes from trailing waves still need to be properly represented in these models via subgrid-scale parameterization or improved resolution.

Acknowledgments. The DEEPWAVE program was made possible through financial and/or in-kind support from many U.S. and international organizations, including the National Science Foundation, National Center for Atmospheric Research/Earth Observing Laboratory, Naval Research Laboratory, German Aerospace Center (DLR), National Institute of Water and Atmosphere Research (NIWA), Australian Antarctic Division (AAD), the New Zealand MET Service, PAE Ltd., ECMWF, and NOAA-NCEP. The authors acknowledge the support of the Chief of Naval Research through the NRL Base Program Element (PE) 0601153N and 0602435N, and the support of National Science Foundation through Grant AGS1338646. Computational resources were supported by a grant of HPC time from the Department of Defense Major Shared Resource Centers. 


\section{APPENDIX}

\section{Ray-Tracing Calculation}

For a wave packet of the form $\exp [i(k x+l y+m z)]$, the ray trajectory (or ray path) is governed by the grouptrajectory ray equation (Lighthill 1978):

$$
\frac{d_{g} x_{i}}{d t}=U_{i}+c_{g i}
$$

where $d_{g} / d t=\partial / \partial t+\left(\mathbf{U}+\mathbf{c}_{g}\right) \cdot \nabla$ represents time rate of change along a ray path and the indices $i=1,2$, and 3 correspond to the three dimensions $x, y$, and $z$. For a hydrostatic gravity wave $(\mathrm{GW})$, the group velocity $\mathbf{c}_{g}$ is given by

$$
\mathbf{c}_{g}=\frac{N^{2}}{\Omega m^{2}}\left[k, l,-K^{2} / m\right],
$$

where $N=\sqrt{(g / \bar{\theta})(d \bar{\theta} / d z)}$ is the buoyancy frequency, $\bar{\theta}$ is the horizontally averaged potential temperature, and $m$ is the vertical wavenumber, which can be written as

$$
m^{2}=\frac{N^{2} K^{2}}{\Omega^{2}-f^{2}} .
$$

For simplicity, we ignore the latitudinal variation of $f$ and horizontal variation of the buoyancy-frequency $N$, and the equations that govern wave refraction in a sheared flow are (e.g., Dunkerton 1984; Eckermann 1992)

$$
\begin{aligned}
& \frac{d_{g} k}{d t}=-k \frac{\partial U}{\partial x}-l \frac{\partial V}{\partial x}, \\
& \frac{d_{g} l}{d t}=-k \frac{\partial U}{\partial y}-l \frac{\partial V}{\partial y} .
\end{aligned}
$$

The ray path, $\mathbf{X}=[x(t), y(t), z(t)]$, for a three-dimensional wave packet with an initial wavenumber vector $\mathbf{K}_{0}=$ $\left(k_{0}, l_{0}\right)$ at location $\mathbf{X}_{0}=\left(x_{0}, y_{0}, z_{0}\right)$ can be computed by numerically forward-integrating Eq. (A1), (A4), and (A5) in time.

\section{REFERENCES}

Alexander, M. J., and H. Teitelbaum, 2011: Three-dimensional properties of Andes mountain waves observed by satellite: A case study. J. Geophys. Res., 116, D23110, https://doi.org/ 10.1029/2011JD016151.

- and A. W. Grimsdell, 2013: Seasonal cycle of orographic gravity wave occurrence above small islands in the Southern Hemisphere: Implications for effects on the general circulation. J. Geophys. Res. Atmos., 118, 11589-11599, https:// doi.org/10.1002/2013JD020526.

—, S. D. Eckermann, D. Broutman, and J. Ma, 2009: Momentum flux estimates for South Georgia Island mountain waves in the stratosphere observed via satellite. Geophys. Res. Lett., 36, L12816, https://doi.org/10.1029/2009GL038587.

Daley, R., and E. Barker, 2001: NAVDAS: Formulation and diagnostics. Mon. Wea. Rev., 129, 869-883, https://doi.org/ 10.1175/1520-0493(2001)129<0869:NFAD>2.0.CO;2.

Doyle, J. D., and Q. Jiang, 2006: Observations and numerical simulations of mountain waves in the presence of directional wind shear. Quart. J. Roy. Meteor. Soc., 132, 1877-1905, https://doi.org/10.1256/qj.05.140.

,,-- R. Smith, and V. Grubišić, 2011: Three-dimensional characteristics of stratospheric mountain waves during T-REX. Mon. Wea. Rev., 139, 3-23, https://doi.org/10.1175/2010MWR3466.1.

Dunkerton, J. T., 1984: Inertia-gravity waves in the stratosphere. J. Atmos. Sci., 41, 3396-3404, https://doi.org/10.1175/15200469(1984)041<3396:IWITS>2.0.CO;2.

Eckermann, S. D., 1992: Ray-tracing simulation of the global propagation of inertia gravity waves through the zonally averaged middle atmosphere. J. Geophys. Res., 97, 1584915 866, https://doi.org/10.1029/92JD01410.

_ mountain waves from space. Science, 286, 1534-1537, https:// doi.org/10.1126/science.286.5444.1534.

_ wave activity in the winter subtropical stratosphere over Australia and Africa. Geophys. Res. Lett., 39, L21807, https:// doi.org/10.1029/2012GL053791.

- J. Ma, D. L. Wu, and D. Broutman, 2007: A three-dimensional mountain wave imaged in satellite radiance throughout the stratosphere: Evidence of the effects of directional wind shear. Quart. J. Roy. Meteor. Soc., 133, 1959-1975, https://doi.org/ 10.1002/qj.187.

_ J. Jindeman, D. Broutman, J. Ma, and Z. Boybeyi, 2010: Momentum fluxes of gravity waves generated by variable Froude number flow over three-dimensional obstacles. J. Atmos. Sci., 67, 2260-2278, https://doi.org/10.1175/ 2010JAS3375.1.

_ , and Coauthors, 2016: Dynamics of orographic gravity waves observed in the mesosphere over the Auckland Islands during the Deep Propagating Gravity Wave Experiment (DEEPWAVE). J. Atmos. Sci., 73, 3855-3876, https://doi.org/ 10.1175/JAS-D-16-0059.1.

Ehard, B., and Coauthors, 2017: Horizontal propagation of largeamplitude mountain waves into the polar night jet. J. Geophys. Res. Atmos., 122, 1423-1436, https://doi.org/10.1002/ 2016JD025621.

Eliassen, A. N., and E. Palm, 1961: On the transfer of energy in stationary mountain waves. Geofys. Publ., 22 (3), 1-23.

Fels, S., and R. S. Lindzen, 1974: Interaction of thermally excited gravity waves with mean flows. Geophys. Fluid Dyn., $\mathbf{5}$ 149-191, https://doi.org/10.1080/03091927409365793.

Fritts, D. C., and M. J. Alexander, 2003: Gravity wave dynamics and effects in the middle atmosphere. Rev. Geophys., 41, 1003, https://doi.org/10.1029/2001RG000106.

— , and Coauthors, 2016: The Deep Propagating Gravity Wave Experiment (DEEPWAVE): An airborne and ground-based exploration of gravity wave propagation and effects from their sources throughout the lower and middle atmosphere. Bull. Amer. Meteor. Soc., 97, 425-453, https://doi.org/10.1175/ BAMS-D-14-00269.1.

Fu, Q., K. N. Liou, M. C. Cribb, T. P. Charlock, and A. Grossman, 1997: Multiple scattering parameterization in thermal infrared radiative transfer. J. Atmos. Sci., 54, 2799-2812, https://doi.org/ 10.1175/1520-0469(1997)054<2799:MSPITI>2.0.CO;2. 
Garfinkel, C. I., and L. D. Oman, 2018: Effect of gravity waves from small islands in the Southern Ocean on the Southern Hemisphere atmospheric circulation. J. Geophys. Res. Atmos., 123, 1552-1561, https://doi.org/10.1002/2017JD027576.

Gregory, K. D., and B. R. Sutherland, 2010: Transmission and reflection of internal wave beams. Phys. Fluids, 22, 106601, https://doi.org/10.1063/1.3486613.

Grubišić, V., and B. J. Billings, 2008: Climatology of the Sierra Nevada mountain-wave events. Mon. Wea. Rev., 136, 757-768, https://doi.org/10.1175/2007MWR1902.1.

Hendricks, E. A., J. D. Doyle, S. D. Eckermann, Q. Jiang, and P. A. Reinecke, 2014: What is the source of the stratospheric gravity wave belt in austral winter? J. Atmos. Sci., 71, 1583-1592, https://doi.org/10.1175/JAS-D-13-0332.1.

Hodur, R. M., 1997: The Naval Research Laboratory's Coupled Ocean/Atmospheric Mesoscale Prediction System (COAMPS). Mon. Wea. Rev., 125, 1414-1430, https://doi.org/10.1175/15200493(1997)125<1414:TNRLSC $>2.0$. CO;2.

Hoffmann, L. X., M. Xue, and M. J. Alexander, 2013: A global view of stratospheric gravity wave hotspots located with Atmospheric Infrared Sounder observations. J. Geophys. Res. Atmos., 118, 416-434, https://doi.org/10.1029/2012JD018658.

Hogan, T. F., and Coauthors, 2014: The Navy Global Environmental Model. Oceanography, 27 (1), 116-125, https://doi.org/ 10.5670/oceanog.2014.73.

Jiang, J. H., D. L. Wu, and S. D. Eckermann, 2002: Upper Atmosphere Research Satellite (UARS) MLS observation of mountain waves over the Andes. J. Geophys. Res., 107, 8273, https://doi.org/10.1029/2002JD002091.

Jiang, Q., R. B. Smith, and J. D. Doyle, 2008: Impact of the atmospheric boundary layer on mountain waves. J. Atmos. Sci., 65, 592-608, https://doi.org/10.1175/2007JAS2376.1.

_ J. D. Doyle, P. A. Reinecke, R. Smith, and S. D. Eckermann, 2013: A modeling study of stratospheric waves over the Southern Andes and Drake Passage. J. Atmos. Sci., 70, 16681689, https://doi.org/10.1175/JAS-D-12-0180.1.

_ P. A. Reinecke, and J. D. Doyle, 2014: Orographic wave drag over the Southern Ocean: A linear theory perspective. J. Atmos. Sci., 71, 4235-4252, https://doi.org/10.1175/JAS-D-14-0035.1.

Jones, W. L., 1967: Propagation of internal gravity waves in fluids with shear flow and rotation. J. Fluid Mech., 30, 439-448, https://doi.org/10.1017/S0022112067001521.

Kain, J. S., and J. M. Fritsch, 1993: Convective parameterization for mesoscale models: The Kain-Fritsch scheme. The Representation of Cumulus Convection in Numerical Models, Meteor. Monogr., No. 46, Amer. Meteor. Soc., 165-170.

Kitchen, E. H., and M. E. McIntyre, 1980: On whether inertiogravity waves are absorbed or reflected when their intrinsic frequency is Doppler-shifted towards f.J. Meteor. Soc. Japan, 58, 118-125, https://doi.org/10.2151/jmsj1965.58.2_118.

Klemp, J. B., and D. R. Durran, 1983: An upper boundary condition permitted internal gravity wave radiation in numerical mesoscale models. Mon. Wea. Rev., 111, 430-444, https://doi.org/ 10.1175/1520-0493(1983)111<0430:AUBCPI >2.0.CO;2.

Krisch, I., and Coauthors, 2017: First tomographic observations of gravity waves by the infrared limb imager GLORIA. Atmos. Chem. Phys., 17, 14 937-14 953, https://doi.org/10.5194/acp-1714937-2017.

Kruse, C., and R. Smith, 2015: Gravity wave diagnostics and characteristics in mesoscale fields. J. Atmos. Sci., 72, 43724392, https://doi.org/10.1175/JAS-D-15-0079.1.

Lane, T. P., M. L. Reeder, B. R. Morton, and T. L. Clark, 2000: Observations and numerical modeling of mountain waves over the southern Alps of New Zealand. Quart. J. Roy. Meteor. Soc., 126, 2765-2788, https://doi.org/10.1002/qj.49712656909.

Lighthill, J., 1978: Waves in Fluids. Cambridge University Press, $504 \mathrm{pp}$.

Lindzen, R. S., 1981: Turbulence and stress due to gravity wave and tidal breakdown. J. Geophys. Res., 86, 9707-9714, https:// doi.org/10.1029/JC086iC10p09707.

, and J. R. Holton, 1968: A theory of the quasi-biennial oscillation. J. Atmos. Sci., 25, 1095-1107, https://doi.org/10.1175/ 1520-0469(1968)025<1095:ATOTQB > 2.0.CO;2.

Louis, J. F., 1979: A parametric model of vertical eddy fluxes in the atmosphere. Bound.-Layer Meteor., 17, 187-202, https:// doi.org/10.1007/BF00117978.

— M. Tiedtke, and J. F. Geleyn, 1982: A short history of the operational PBL parameterization at ECMWF. Proc. Workshop on Planetary Boundary Layer Parameterization, Reading, United Kingdom, ECMWF, 59-79.

McLandress, C., T. G. Shepherd, S. Polavarapu, and S. R. Beagley, 2012: Is missing orographic gravity wave drag near $60^{\circ} \mathrm{S}$ the cause of the stratospheric zonal wind biases in chemistryclimate models? J. Atmos. Sci., 69, 802-818, https://doi.org/ 10.1175/JAS-D-11-0159.1.

Mellor, G. L., and T. Yamada, 1974: A hierarchy of turbulence closure models for planetary boundary layers. J. Atmos. Sci., 31, 1791-1806, https://doi.org/10.1175/1520-0469(1974) 031<1791:AHOTCM > 2.0.CO;2.

Pautet, P.-D., and Coauthors, 2016: Large amplitude mesospheric response to an orographic wave generated over the Southern Ocean Auckland Islands $\left(50.7^{\circ} \mathrm{S}\right)$ during the DEEPWAVE project. J. Geophys. Res. Atmos., 121, 1431-1441, https:// doi.org/10.1002/2015JD024336.

Preusse, P., A. Dörnbrack, S. D. Eckermann, M. Riese, B. Schaeler, J. T. Bacmeister, D. Broutman, and K. U. Grossmann, 2002: Space-based measurements of stratospheric mountain waves by CRISTA 1. Sensitivity, analysis method, and a case study. J. Geophys. Res., 107, 8178, https://doi.org/10.1029/2001JD000699.

Reinecke, P. A., and D. R. Durran, 2008: Estimating topographic blocking using a Froude number when the static stability is nonuniform. J. Atmos. Sci., 65, 1035-1048, https://doi.org/ 10.1175/2007JAS2100.1.

Rutledge, S. A., and P. V. Hobbs, 1983: The mesoscale and microscale structure of organization of clouds and precipitation in midlatitude cyclones. VIII: A model for the "seederfeeder" process in warm-frontal rainbands. J. Atmos. Sci., 40, 1185-1206, https://doi.org/10.1175/1520-0469(1983)040<1185: TMAMSA $>2.0 . \mathrm{CO} ; 2$.

Sato, K., S. Tateno, S. Watanabe, and Y. Kawatani, 2012: Gravity wave characteristics in the Southern Hemisphere revealed by a high-resolution middle-atmosphere general circulation model. J. Atmos. Sci., 69, 1378-1396, https://doi.org/10.1175/ JAS-D-11-0101.1.

Shutts, G. J., and S. B. Vosper, 2011: Stratospheric gravity waves revealed in NWP model forecasts. Quart. J. Roy. Meteor. Soc., 137, 303-317, https://doi.org/10.1002/qj.763.

Smith, R. B., 1980: Linear theory of stratified hydrostatic flow past an isolated mountain. Tellus, 32, 348-364, https://doi.org/ 10.3402/tellusa.v32i4.10590.

1989: Mountain-induced stagnation points in hydrostatic flow. Tellus, 41A, 270-274, https://doi.org/10.1111/j.16000870.1989.tb00381.x.

, 2002: Stratified airflow over topography. Environmental Stratified Flows, R. Grimshaw, Ed., Topics in Environmental Fluid Mechanics, Vol. 3, Kluwer, 119-159. 
S. T. Skubis, J. D. Doyle, A. Broad, C. Kiemle, and H. Volkert, 2002: Mountain waves over Mt. Blanc: Influence of a stagnant boundary layer. J. Atmos. Sci., 59, 2073-2092, https://doi.org/10.1175/1520-0469(2002)059<2073:MWOMBI $>$ 2.0.CO;2.

- and Coauthors, 2016: Stratospheric gravity wave fluxes and scales during DEEPWAVE. J. Atmos. Sci., 73, 2851-2869, https://doi.org/10.1175/JAS-D-15-0324.1.

Thompson, W. T., and S. D. Burk, 1991: An investigation of an Arctic front with a vertically nested mesoscale model. Mon. Wea. Rev., 119, 233-261, https://doi.org/10.1175/1520-0493(1991) 119<0233:AIOAAF>2.0.CO;2.

Volkert, H., C. Keil, C. Kiemle, G. Poberaj, J.-P. Chaboureau, and E. Richard, 2003: Gravity waves over the eastern Alps: A synopsis of the 25 October 1999 event (IOP-10) combining insitu and remote sensing measurements with a high-resolution simulation. Quart. J. Roy. Meteor. Soc., 129, 777-797, https:// doi.org/10.1256/qj.02.45.

Vosper, S. B., 2015: Mountain waves and wakes generated by South Georgia: Implications for drag parameterization. Quart. J. Roy. Meteor. Soc., 141, 2813-2827, https://doi.org/10.1002/qj.2566.

Wu, D. L., and J. W. Waters, 1996: Satellite observations of atmospheric variances: A possible indication of gravity waves. Geophys. Res. Lett., 23, 3631-3634, https://doi.org/10.1029/ 96GL02907.

_ - and S. D. Eckermann, 2008: Global gravity wave variances from Aura MLS: Characteristics and interpretation. J. Atmos. Sci., 65, 3695-3718, https://doi.org/10.1175/2008JAS2489.1. 